\title{
Review Article \\ Oligodendrocyte Precursor Cells in Spinal Cord Injury: A Review and Update
}

\author{
Ning Li and Gilberto K. K. Leung \\ Department of Surgery, Li Ka Shing Faculty of Medicine, The University of Hong Kong, Queen Mary Hospital, Pokfulam, Hong Kong \\ Correspondence should be addressed to Gilberto K. K. Leung; gilberto@hku.hk
}

Received 12 March 2015; Revised 19 June 2015; Accepted 25 June 2015

Academic Editor: Markus Kipp

Copyright (C) 2015 N. Li and G. K. K. Leung. This is an open access article distributed under the Creative Commons Attribution License, which permits unrestricted use, distribution, and reproduction in any medium, provided the original work is properly cited.

\begin{abstract}
Spinal cord injury (SCI) is a devastating condition to individuals, families, and society. Oligodendrocyte loss and demyelination contribute as major pathological processes of secondary damages after injury. Oligodendrocyte precursor cells (OPCs), a subpopulation that accounts for 5 to $8 \%$ of cells within the central nervous system, are potential sources of oligodendrocyte replacement after SCI. OPCs react rapidly to injuries, proliferate at a high rate, and can differentiate into myelinating oligodendrocytes. However, posttraumatic endogenous remyelination is rarely complete, and a better understanding of OPCs' characteristics and their manipulations is critical to the development of novel therapies. In this review, we summarize known characteristics of OPCs and relevant regulative factors in both health and demyelinating disorders including SCI. More importantly, we highlight current evidence on post-SCI OPCs transplantation as a potential treatment option as well as the impediments against regeneration. Our aim is to shed lights on important knowledge gaps and to provoke thoughts for further researches and the development of therapeutic strategies.
\end{abstract}

\section{Introduction}

Spinal cord injury (SCI) is a catastrophic event that commonly results in axonal injuries and deaths of neurons and glial cells. Subsequent secondary injuries that consist of uncontrolled inflammation, excitotoxicity, edema, ischemia, and chronic demyelination can lead to additional damages, while the formation of glial scars also prohibits axonal regeneration [1] (Figure 1). SCI causes disturbances to normal sensory, motor, or autonomic functions and can significantly affect patients' physical, mental, and social well-being [2, 3]. Current therapies mainly rely on early operations for mechanical decompression, symptomatic relief, supportive care, and rehabilitation. With the development of stem cell technologies, cell-based transplantation is now thought to be a promising therapeutic approach for SCI. In fact, an autologous bone marrow stem cell transplantation approach is already undergoing a phase II clinical trial (NCT02009124, https://clinicaltrials.gov/), while a neural stem cell transplantation study is currently in phase I/II trial (NCT02326662, https://clinicaltrials.gov/). Though exciting, their clinical utilities are still far from being clear partially due to unclear safety issues such as teratoma formation.

A potentially useful cell source for post-SCI transplantation is oligodendrocyte precursor cells (OPCs). The latter are the major source of oligodendrocytes responsible for myelination within the central nervous system (CNS). The proliferation, migration, and differentiation of OPCs are sophisticatedly regulated by numerous factors including neuronal- or axonal-glial neurotransmitters, growth factors, neurotrophins, and transcription factors. The majority of OPCs are quiescent with limited self-division under normal circumstances, but they may respond rapidly to injuries and, in particular, demyelination. However, their rescuing effects are commonly hindered by the hostile microenvironment at the injury sites, leading to incomplete remyelination and clinical recovery. Therefore, finding ways to boost endogenous OPCs by enhancing the positive regulatory factors while attenuating negative ones has been an area of intense investigations in neurotrauma research. 


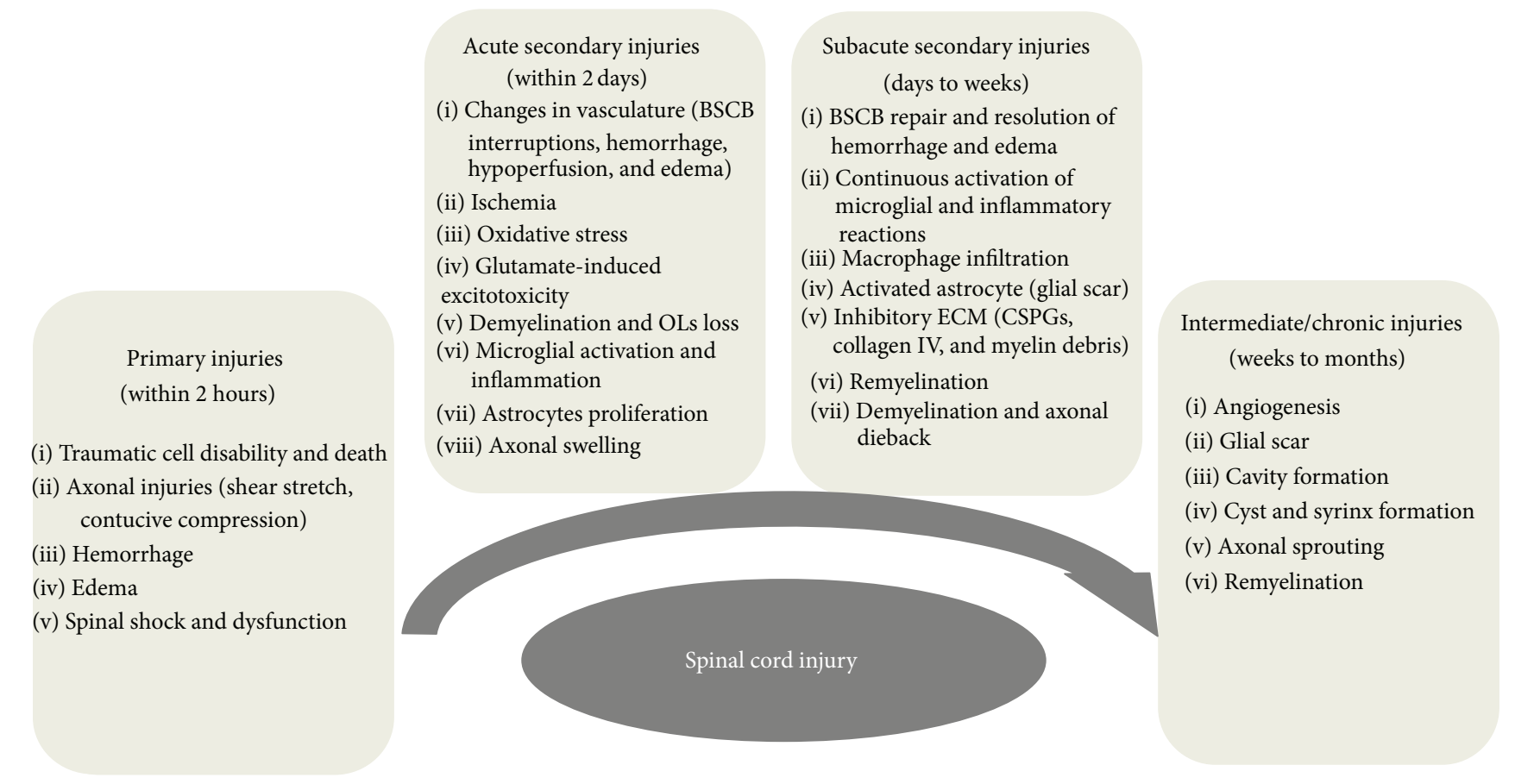

FIGURE 1: The major pathophysiological phases after spinal cord injuries. BSCB: blood-spinal cord barrier; OLs: oligodendrocytes; ECM: extracelluar matrix; CSPGs: chondroitin sulfate proteoglycans.

This review will first summarize known characteristics of OPCs and then focus on the current understandings about the potential roles of OPCs in SCI, in particular, their effects on remyelination and glial scars formation. Recent progress in OPCs transplantation research and associated concerns will be discussed as well. Our aim is to shed lights on important knowledge gaps and to provoke thoughts for further researches and therapeutic treatment strategies.

\section{Oligodendrocytes Loss and Demyelination after Spinal Cord Injury}

The myelin sheaths are essential for saltatory signal conduction and tropic support to maintain axonal integrity [4]. Unfortunately, mature oligodendrocytes, the only myelinforming cells within the CNS, are highly susceptible to damages [5]. Grossman et al. observed an acute loss of oligodendrocytes, along with neuronal death, as early as 15 minutes after injury in a rat spinal contusion model [6] and which might last for 3 to 7 days [7]. In an observational study with a 450-day follow-up after contusive SCI in adult rats, the extent of demyelination significantly dropped within one week after injury, followed by fluctuations at a lower level for about 70 days, and then increased steeply during the rest of the observation period. The findings suggested a chronic ongoing process of aggravated demyelination [8].

The underlying mechanisms are far from clear, however. Besides the initial acute insults, both necrosis and apoptosis of oligodendrocytes have been observed in the chronic phase of injury [9-12]. Numerous factors may contribute to this process including the overabundant release of proinflammatory cytokines such as tumor necrosis factor- $\alpha$ (TNF- $\alpha$ ) and interleukin-1 $\beta$ (IL-1 $\beta$ ), uncontrolled oxidative stress, and ischemia as well as glutamate- and ATP-mediated excitotoxicity $[12,13]$. It is worth pointing out that though autophagy, another type of cell death, has been shown to cause oligodendrocytes death $[14,15]$, its positive and negative impacts remain controversial. Smith et al. demonstrated that autophagy did not increase oligodendrocyte loss in the spinal cord upon terminal deoxynucleotidyl transferase dUTP nick end labeling (TUNEL) assay and caspase-3 immunostaining; instead, autophagy was found to promote myelin development [16].

Historically, it was thought that oligodendrocytes and intact myelin sheath were primarily responsible for the facilitation of neuronal signal conduction only. The potential role of oligodendrocytes in preserving the integrity and survival of axons was not realized until Griffiths and McCulloch reported acute retraction of some lateral loops from paranode at 1.5 hours after injury due to oligodendrocytes loss [17]. Given the fact that each oligodendrocyte is responsible for 30-80 distinct axons, it could be expected that extensive demyelination may occur even after the collapse of only a single oligodendrocyte $[18,19]$. Indeed, transgenic mice with mutated myelin proteins such as myelin proteolipid protein (PLP) and DM-20 were found to show overt axonal swelling and degeneration [20]. Similar observations were also made in mice harboring mutations of other matureoligodendrocyte-related proteins or genes [21-23]. Together, these findings have given rise to the current concept that axonal integrity relies heavily on oligodendrocyte support and that oligodendrocyte loss would result in axonal degeneration. 
It is known that axons of cortical neuron may project as far as $100 \mathrm{~cm}$ within the corticospinal tract [24]. Besides, myelin sheaths essentially shield axons from their surroundings and limit access to extracellular metabolites. These raise concerns about metabolic homoeostasis and energy supply to the axons. In this regard, oligodendrocytes have been shown to produce lactate, an alternative energy source for axons within the CNS [25-27]. Reducing MCT-1, one of the monocarboxylate transporters (MCTs) in oligodendrocytes, resulted in severe axonal swelling, indicative of the important role of oligodendrocyte-derived lactate [28]. Furthermore, myelinating oligodendrocytes were able to synthesize and deliver ATP to axons through connexons, a kind of gap junctions protein $[29,30]$. This increases the conduction speed of action potentials [31]. Other factors responsible for axonal development and stabilization include $2^{\prime}, 3^{\prime}$-cyclic nucleotide phosphodiesterase 1 (CNP-1) gene [32] and peroxisomal targeting signal 1 receptor (PEX5) gene [33]. These findings suggest that, in addition to their predominant functions in nerve conduction, oligodendrocytes may also labor as mechanical and trophic supports to axons [24, 26]. As naked or demyelinated axons are more vulnerable to injuries, it is reasonable to expect that, after injury, efficient remyelination is critical not only for cellular replacement but also neuron-glial cross talk reconstruction and neuronal function recovery.

\section{Oligodendrocyte Precursor Cells and Their Characteristics}

3.1. Multipotency of Oligodendrocyte Precursor Cells. Vaughn and Peters first discovered a type of small and irregularly shaped cells with stout processes that were without astrocytes or oligodendrocytes characteristics in adult, embryonic, and perinatal rat optic nerves [49]. On autoradiography, these cells reacted to Wallerian degeneration and represented 85$90 \%$ of proliferating cells after degeneration despite the fact that they only accounted for $\sim 5 \%$ of all glia under normal conditions $[50,51]$. These cells were initially termed "oligodendrocyte-type-2 astrocyte (O-2A) progenitor cells" due to their potencies for developing into either oligodendrocytes or type-2 astrocytes under specific conditions [5254]. More recently, these cells were renamed "oligodendrocyte precursor cells (OPCs)" because of their predominant function of regenerating oligodendrocytes in demyelinating conditions [55]. OPCs are found in both white and gray matters within the CNS though abundantly so in the former [56]. Morphologically, OPCs have small cell bodies and multiple processes and may adopt a bipolar or tripolar shape [57].

Interestingly, the terminology of OPCs has received further challenges because of recent discoveries of their abilities to give rise to neurons. Purified OPCs from postnatal day 6 rat optic nerve have been shown to revert back to multiple CNS stem cells, which could in turn give rise to neurons and oligodendrocytes as well type- 1 and type- 2 astrocytes [58]. Although these findings were initially challenged on the ground of experimental techniques [59], they were subsequently confirmed both in vitro and in vivo $[60,61]$. Guo et al. detected low expression of doublecortin (DCX), a marker for migrating and immature neurons, in a population of cells with negative $\mathrm{HuC} / \mathrm{D}$ signals (exclusively presented in neurons) but positive PDGFR- $\alpha$ and Sox10 signals, both of which are determinating markers of final oligodendrocyte maturation [62]. These DCX+/PDGFR- $\alpha+/ \mathrm{HuCD}$ - cells raised thoughts about the idea that at least some endogenous OPCs do have characteristics of neurons. Indeed, using PDGFR- $\alpha$ promoter-driven Cre, scientists were able to induce neuronal formation from OPCs in adult piriform cortex [63]. Similar findings were also observed in vivo within adult rat neocortex [64], neonatal mouse forebrain [65], and postnatal cerebral cortex [62].

3.2. OPCs as Postsynaptic Neuronal Regulatory Targets. The conventional dogma that classic chemical synapses exist exclusively as neuron-neuron connections was challenged by the discovery of functional glutamatergic synapses between OPCs and axons [66-69]. The latter would include N-methylD-aspartate receptor (NMDAR), alpha-amino-3-hydroxy-5methyl-4-isoxazolepropionic acid receptor (AMPAR), and kainite receptors. On oligodendrocytes, these receptors are activated by glutamate released by either neurons or axons, which increases intracellular $\mathrm{Ca}^{2+}$ level through stimulation of voltage-dependent $\mathrm{Ca}^{2+}$ channels or the reversal of $\mathrm{Na}^{+} / \mathrm{Ca}^{2+}$-exchangers. Li et al. demonstrated that NMDA would promote OPCs maturation and myelination in dorsal root ganglions- (DRGs-) OPCs coculture system in vitro [69]. Moreover, glutamate released by cultured cortical neurons could promote OPCs migration by stimulating NMDAR; T lymphoma invasion and metastasis 1 (Tiam1), a Racl guanine nucleotide exchange factor (Racl-GEF) that is coexpressed and interacts with NMDAR in OPCs, would antagonize NMDAR and suppress migration [70].

Remyelination was found to be significantly delayed by the NMDAR specific antagonist MK801 in an in vivo cuprizone demyelination model, suggesting that NMDAR is essential for the entire OPCs-initiated remyelination process [69]. Others such as AMPA-type glutamate receptors may also participate in neuron- and axon-OPCs connections. AMPAR activation appeared to be essential for OPCs morphological alterations rather than proliferation and differentiation during myelination [71]. AMPAR blockade resulted in the inhibition of OPCs morphological development while promoting proliferation and differentiation [72]. Interestingly, a recent study also demonstrated that the degree of OPCs-neuron contacts actually differed between demyelination and remyelination phase in that synapses would only form during remyelination upon sufficient proliferation after demyelination [73]. These findings were derived from a lysolecithin- (LPC-) induced demyelination model, however, and whether the same would apply in SCI remains to be tested. It is plausible that OPCs may lack glutamatergic synapses immediately after injury in order to promote selfproliferation, and synaptic inputs would only develop during the migration and maturation stages in preparation for further remyelination. And to accomplish final myelin sheaths 
formation, a subsequent regain of AMPA synapses may be required for correct morphological development.

More than $90 \%$ of synaptic currents in OPCs in the neocortex are evoked by gamma-aminobutyric acid-ergic (GABAergic) synapse [74], and GABAergic connections between neuronal axon and OPCs are abundant $[75,76]$. As in the case of glutamatergic receptors, activation of GABA- $\alpha$ receptors may trigger $\mathrm{Ca}^{2+}$ influx via $\mathrm{Na}^{+} / \mathrm{Ca}^{2+}$ exchangers and promote OPCs migration [77]. In light of this evidence, it is highly likely that $\mathrm{Ca}^{2+}$ influx triggered by either glutamatergic or GABAergic synapses is essential for OPCs migration by means of cytoskeletal reorganization, cell mobility, membrane traffic, and cell adhesion and deadhesion [78]. On the other hand, a more complex case is found in a cerebellar diffuse white matter injury model in which hypoxia-induced loss of GABA- $\alpha$ receptormediated synaptic input to OPCs significantly suppressed OPCs maturation while promoting proliferation [79]. In this regard, it seems that depolarization or hyperpolarization of GABAergic synapses contributes to different aspects of OPCs regulation. The expression of GABA- $\beta$ receptors on OPCs and their physiological functions is incompletely understood. It is known that both GABA- $\beta 1$ and GABA- $\beta 2$ subunits are localized on OPCs and that stimulating GABA- $\beta$ receptors by baclofen, a selective agonist, substantially increases migration and proliferation, providing evidence for a functional role of GABA- $\beta$ receptors in oligodendrocyte development [80]. The temporal-spacial alteration of either type of GABAergic synapses after CNS injury and the effect on OPCs and posttraumatic remyelination are not yet clear.

Purinergic receptors, including $\mathrm{P} 1$ receptors (alternatively termed as adenosine receptors), metabotropic $\mathrm{P} 2 \mathrm{Y}$ receptors, and ionotropic P2X receptors, are widely distributed in neurons and glial cells. As the breakdown product of ATP, adenosine is the main ligand targeting four subtypes of adenosine receptors ( $\mathrm{A} 1, \mathrm{~A} 2 \mathrm{a}, \mathrm{A} 2 \mathrm{~b}$, and $\mathrm{A} 3$ receptors), all of which have been identified in OPCs [81]. Activation of adenosine receptors evokes the alteration of $\mathrm{Ca}^{2+}$ signals via G-protein coupled receptors in OPCs and regulates their differentiation and myelination. Particularly, activation of A1 receptor may be indispensable in recruiting OPCs to sites of injury where remyelination occurs [82]. Contrarily, A2 receptors may possibly act in a different way since they simulate cyclic adenosine monophosphate (cAMP) via $G_{s}$ receptors rather than $G_{i}$ receptors as for $A 1$ receptors. Indeed, selective A2a receptor activation may suppress OPCs proliferation in vitro through the inhibition of $\mathrm{K}^{+}$currents [83]. Though little knowledge is provided yet, it is highly believed that figuring out the effects of $\mathrm{A} 2 \mathrm{~b}$ receptors upon OPCs may offer more information in regulating them under pathological circumstances since it is shown that higher concentration of adenosine is needed for activation of $\mathrm{A} 2 \mathrm{~b}$ receptors, which probably can be detected in trauma, hypoxia, or ischemia [84].

Adenine (i.e., ATP and ADP) and uracil nucleotides (i.e., UTP and UDP) activate $\mathrm{P} 2$ receptors rather than adenosine receptors. Activating $\mathrm{P} 2 \mathrm{X} 7$, the only functionally active $\mathrm{P} 2 \mathrm{X}$ receptor in OPCS, results in a sustained influx of $\mathrm{Ca}^{2+}$ and regulates pathological responses of OPCs [85]. There is strong evidence that blocking $\mathrm{P} 2 \mathrm{X} 7$ can have a neuroprotective effect against ATP-induced oligodendrocytes-toxicity [86] and that downregulation of $\mathrm{P} 2 \mathrm{X} 7$ receptors expression may occur after hypoxic ischemic injury [87]. While metabotropic P2Y receptors may or may not be directly related to cell viability, their involvements in promoting OPCs migration [88] and prohibiting proliferation [85] have been reported. The functions of other $\mathrm{P} 2 \mathrm{Y}$ receptors subtypes such as $\mathrm{P} 2 \mathrm{Y} 2$, $\mathrm{P} 2 \mathrm{Y} 4$, and P2Y12 in OCPs and SCI are even less well understood and deserve further investigations $[89,90]$.

The expression of muscarinic acetylcholine (mACh) receptors, a subtype of cholinergic receptors, has been successfully identified on OPCs [91]. Activation of mACh may rescue OPCs from growth factor deprivation [92]. Alternatively, mACh receptors activation significantly promotes OPCs proliferation while prohibiting their maturation [93]. Conversely, antimuscarinic adjunct therapy was found to offer a prodifferentiative effect in human OPCs in vitro. Enhanced functional recoveries were also shown with systemic treatment with $\mathrm{mACh}$ receptors antagonist following transplantation of human OPCs into hypomyelinated rats [94]. The role of nicotinic acetylcholine ( $\mathrm{nACh}$ ) receptors, which are expressed on OPCs also, is not yet known $[95,96]$.

3.3. Regulation of Oligodendrocyte Precursor Cells. OPCs functions are intricately modulated by a complex network of growth factors, cytokines and chemokines, neurotrophins, and transcription factors, all of which would affect the remyelinating process in SCI.

Growth Factors. Platelet-derived growth factor-A (PDGFA) and fibroblast growth factor-2 (FGF-2) are two classic factors affecting oligodendrocyte lineage development. Stable expression of PDGFR- $\alpha$ in OPCs and the mitogenic effect of PDGF-A, a ligand to PDGFR- $\alpha$, in oligodendrocyte lineage have been long established [57]. OPCs in white matter respond to PDGF-A stimulation via $\mathrm{Wnt} / \beta$-catenin and phosphatidylinositol 3-kinase pathways by increasing proliferation rate [97]. The evidence that PDGF-A stimulus may accelerate the migration of OPCs by activating ERK pathway gives thought to its potential prorecruitment role on OPCs after SCI [98]. FGF-2 is another strong mitogen to OPCs. Direct intraventricular injection of FGF-2 after subventricular zone dissection injury not only enhanced the generation of OPCs but also promoted the differentiation of oligodendrocytes from OPCs [99]. In agreement with this, a double knockout of FGF receptors 1 and 2 significantly impacted on the differentiation of OPCs and hindered myelin sheaths formation in a chronic cuprizoneinduced demyelination model but not in acute demyelination in the same study [100]. Interestingly, proliferation of OPCs can be induced in culture of conditioned medium from B104 neuroblastoma cells, possibly due to the coexistence and synergy of PDGF-A and FGF-2 [101]. Other growth factors include insulin-like growth factor (IGF), which has synergic functions with PDGF and FGF through common downstream messengers like PI3K/AKT and ERK pathways.

Ciliary neurotrophic factor (CNTF), a pleiotropic cytokine within the IL- 6 family, has been shown to promote 
spinal cord-derived OPCs survival and differentiation in culture as well as endogenous OPCs migration in an acute demyelination model $[102,103]$. In the situation of SCI, a chronic and continua increase of CNTF level was observed in contusive spinal cord tissues, especially along the border of injury site where posttraumatic oligodendrogenesis was severe [104]. The idea of CNTF being involved in the regulation of OPCs after SCI is supported by a recent study showing enhanced remyelination and functional recovery after transplantation of CNTF-expressing adult OPCs into contused spinal cord [34].

Neurotrophins. Neurotrophins are responsible for the regulation of survival and development of neural cells including neurons and progenitor cells. Direct promyelinating effect of brain-derived neurotrophic factor (BDNF) via activation of $\operatorname{TrkB}$ receptors has been demonstrated in dorsal root ganglions- (DRGs-) OPCs coculture system [105]. Consistently, deletion of TrkB receptors in mice reduced thickness of myelin sheath but would have no effect on oligodendrocyte maturation or the number of myelinated axons. Surprisingly, knockout of TrkB receptors actually led to a significant increase in the density of OPCs, suggesting that the regulatory effects of BDNF via TrkB receptors may be phase-dependent [106]. Neurotrophin-3 (NT-3) is another neurotrophin that has a positive role in inducing survival and proliferation of OPCs [107]. Both BDNF and NT-3 expressions increase after SCI in mammals $[108,109]$, and additional NT-3, alone or combined with sonic hedgehog, could increase the number of OPCs and enhance remyelination after SCI [110].

Chemokines and Cytokines. Chemokines are key players in the immunological and hematological systems. They are also coexpressed with neurotransmitters such as choline and dopamine in specific regions of the brain where they serve specific functions $[111,112]$. Though the expression of a number of chemokines would alter after SCI, not all are responsible for OPCs modulation. For example, CCL2 (also known as MCP-1) expression is elevated during the acute phase after spinal cord damaging and its inhibition would attenuate secondary SCI [113]; it does not affect proliferation and myelination of OPCs [114]. In contrast, CXCL12 (SDF-1 $\alpha$ ) and its receptor CXCR4 would promote OPCs proliferation and myelin sheath formation in a dose-dependent matter [114-116]. CXCL1 (GPO- $\alpha$ ) and its receptor CXCR2 may also take part in the regulation of OPCs survival in pathological states. Enrichment of CXCL1 ameliorates OPCs death from inflammation cascade, which is a major component of secondary injury after CNS trauma [117, 118].

It has been demonstrated that the synthesis of several cytokines such as leukemia inhibitory factor (LIF) is upregulated after SCI [119]. LIF is known to promote oligodendrocyte lineage development [120] and protect OPCs after demyelinating injuries and ischemic trauma [121, 122]. Also, transportation of LIF through impaired spinal cord-blood barrier has been observed after SCI [123]. Interferon-gamma (IFN- $\gamma$ ) also exerts interesting dual effects on OPCs in a concentration-dependent manner; it maintains OPCs in the cell cycle at low level of expression, whilst higher levels would cause demyelination [124]. IL-17A is another new candidate that can induce OPCs to exit the cell cycle and commence differentiation into mature oligodendrocytes by activating ERK1/2 pathways in demyelinating pathologies [125]. These effects may occur in conjunction with IL-1 $\beta$, which is known to protect OPCs and promote their differentiation. But unlike IL-17A, IL-1 $\beta$ arrests OPCs in the cell cycle and hinders their mitosis [126]. It would be interesting to study the combined effects of IL-17A and IL-1 $\beta$ upregulation after SCI [119].

Transcription Factors. A vast body of literatures has described the transcriptional networks that regulate OPCs, one of which is the basic helix-loop-helix (bHLH) family. Of particular interest is the significant role played by oligodendrocyte transcription factors 1 (OLIG1) and OLIG2, both being oligodendrocyte-specific genes [127, 128]. Double-mutant OLIG1 and OLIG2 would eliminate the formation of OPCs and the genesis of motor-neurons and oligodendrocytes [129], while transient expression of OLIG1 would induce the formation of OPCs from neural stem cells [130]. For remyelination, a series of loss- and gain-of function in vitro studies have demonstrated the comparatively more predominant role of OLIG2 [131-133]. Overexpression of OLIG2 in transgenic mice may lead to precocious myelination throughout the CNS as well as enhanced OPCs migration and remyelination [134]. OLIG1 and OLIG2 also interact. While OLIG2 expression is upregulated in contused spinal cord [135], its solo overexpressionwould result in tumorous cell growth. Interestingly, such tumorigenesis is absent under the situation of simultaneous expressions of OLIG1 and OLIG2, indicating a directly restrictive and mutually modulatory function between them [136]. Compared with OLIG2, OLIG1 plays a secondary and nonessential role in oligodendrogenesis as OLIG1 null mice lines have shown only a mild delay in oligodendrocyte differentiation and maturation without long-term effect [137].

OLIGs are modulated by other transcription factors such as inhibitor of DNA-binding protein 4 (ID4) and its companion ID2, both of which act as overt transcriptional repressors upon OPCs differentiation and maturation by sequestrating OLIG1 and OLIG2 and preventing them from binding consensus DNA domains $[138,139]$. This indicates a potential modulating role of IDs on OPCs in SCI. Indeed, electroacupuncture treatment after compressive spinal cord injury was found to protect myelin sheath breakdown and increase OPCs proliferation by promoting OLIG2 but attenuating ID2 expression [140].

The high mobility group (HMG) family, another group of transcriptional factors, also modulates OPCs. In particular, SOX5 and SOX6 from D subgroup of HMG are found in OPCs, and they repress the terminal maturation of OPCs and hinder their migration [141]. In OPCs, SOX6 expression requires the consistent presence of SOX8 and SOX9, which guarantee the generation of OPCs in conjunction with SOX10 $[141,142]$. The latter is crucial for the terminal differentiation of OPCs since ablation of SOX10 would lead to an altered migration pattern and reduced quantity of OPCs due to enhanced apoptosis [142]. SOX10 may also act as a regulating target and mediator of OLIG1 and OLIG2 during OPCs 
maturation [136]. The likely synergistic relationship between SOX10, OLIG, and MYRF further complicates the picture and calls for more detailed posttranscriptional studies [143, 144].

Current evidence also suggests the positive participation of ZFP191 and ZFP488, two members of zinc finger transcription factors, in OPC regulations. Mutation of ZFP191 in C3H/HeJ genetic mice would lead to significant hypomyelination with preserved process-outreaching progenitors, indicating that ZFP191 may have a stage-specific action. ZFP488 is an oligodendrocyte-specific regulator. Its overexpression would promote oligodendrocyte precursor formation in cooperation with OLIG2 [145]. Of particular interest is myelin transcription factor 1 (MYT1) which is upregulated in the injured spinal cord [146]. In light of the evidence that MYT1 is crucial for progenitor proliferation and differentiation [147], it is possible that MYT1 may contribute to the modulation of OPCs in SCI. Many other transcription factors such as MASH1 (alternatively known as ASCL1) [148], NKX family [149], and Yin Yang 1 (YY1) [150] may similarly regulate oligodendrocytes generation although concrete evidence is still lacking.

\section{Roles of Oligodendrocyte Precursor Cells after Spinal Cord Injuries}

4.1. Alterations after Spinal Cord Injuries. OPCs respond to SCI rapidly by altering their morphologies and accelerating mitosis $[151,152]$. Overall, the proliferation rate of OPCs would significantly increase by the end of the first day after injury and remain elevated in the following week. Cells number would remain high for a whole month. Two different subtypes of OPCs may be identified within and around the injury site [153]. Round-shaped OPCs with high NG2 staining and short thick processes were found along the injury lesions; this contrasts with OPCs with multiple processes seen 200$300 \mathrm{um}$ away from the lesion. In general, OPCs positively stained for NG2 and BrdU antibodies were found throughout the impact site and the surrounding spared areas in the first week after injury [154]. Elevated proliferation continued for two weeks, followed by a decline within the epicenter and rostral sections but not the caudal parts. Another time-course study described a more rapidly upregulated proliferation by day 2 that peaked by the 4 th day and then declined by week 1 [155]. A closer look at the temporal-spatial pattern showed that, instead of the epicenter, most BrdU+ OPCs were in fact concentrated within $1.5 \mathrm{~mm}$ rostral to the injury site 3 days after SCI [7, 156]; the number of cells labeled with NG2/Ki67 would drop within 4 hours, indicating a local toxic effect after injury [157].

There is hitherto scanty information on the mobility of OPCs after SCI although they are generally thought to migrate at a slower rate than their precursor stem cells [158]. Whether proliferative OPCs around the injury site are activated in situ or derived from immigrating cells remains unknown. Carroll et al. studied experimental demyelinating optic nerve lesions and reported a centripetal migration of cells towards the lesion by day four. Though not firmly identified as OPCs, these cells did differentiate into oligodendrocytes during and after migration [159], and it is possible that the same may occur in SCI. In another study using a spinal contusion injury model, treatment with the enzyme chondroitinase $\mathrm{ABC}$, which removed the inhibitory effects of chondroitin sulfate proteoglycans (CSPGs), could significantly enhance the quantity of OPCs 2-fold [160]. Using double-staining techniques, the authors further demonstrated that none of the OPCs were positive for BrdU/Olig1 or Ki67/Olig1, suggesting that the increase of OPCs number was primarily due to migration rather than in situ proliferation.

\subsection{Remyelination by Endogenous Oligodendrocytes Precursor} Cells. Identifying the exact cell type responsible for remyelination in diseases is critical for the development of therapeutic interventions. Self-mitosis and replacement for the damaged cells are considered as a direct and plausible way of healing and recovery after injuries. As a consequence, mature oligodendrocytes, being the myelin-forming cells in the CNS, were initially thought to be responsible for posttraumatic remyelination [161]. However, this postulation was challenged by the evidence that terminally differentiated oligodendrocytes would represent no more than one-fourth of the total BrdU+ cells in spinal cord tissue following contusive injury [156], and surviving oligodendrocytes after injuries would possess extremely limited abilities to divide [162].

An alternative hypothesis is that OPCs may be responsible for the generation of myelinating cells and remyelination instead $[152,154,163]$. Watanabe et al. found a robust proliferation of OPCs during the first week after chemical-induced demyelination, followed by a steep decline of OPCs with an increase in the number of mature oligodendrocytes [164]. More importantly, a few thin myelin rings were detectable on day 14 , and, by day 28 , numerous myelin basic protein (MBP) positive myelin sheaths were observed throughout the lesion. The results indicated that new matured oligodendrocytes were mainly derived from OPCs and were able to produce myelin sheaths in vivo. Further supporting evidence is made available from transplantation experiments (see below). Cao et al. studied whether treatment with exogenous OPCs could alleviate demyelination and improve motor function [34]. Using OPCs expressing CNTF, grafted cells were found to differentiate into mature oligodendrocytes. Notably, transcranial magnetic motor-evoked potentials (tcMMEPs) and magnetic interenlargement reflex (MIER) showed a progressive recovery in both the CNTF-expressing OPCs group and the control OPCs group; no restoration was detected in nontransplantation groups. In another spinal cord irradiation injury model treated with mouse embryonic stem cells- (mESCs-) derived OPCs, a reduction in lesion volume and an increase in dorsal funiculus density were observed [39]. Forelimb locomotion improved in the transplantation group when compared with controls. These findings suggested that OPCs were able to generate mature oligodendrocytes, which may then become integrated and functional within the injury site.

It is important to note that OPCs may not be the only endogenous progenitors of myelinating oligodendrocytes after spinal cord trauma. Ependymal cells, located in the central canal of spinal cord, possess neural stem/progenitor cell properties and may respond extensively to insulting 
signals in spinal cord tissue. Such proliferative responses seem to be exclusive to spinal cord trauma and do not occur after chemical-induced demyelination [165]. Though, under normal circumstances, the proliferative activity of ependymal cells is only a tenth of that of OPCs, as soon as injury takes place, ependymal cells would produce as much as double the number of progenies compared to OPCs. Excitingly, a fraction of these cells would finally differentiate into functioning oligodendrocytes [166]. A recent study has demonstrated the cholinergic enhancement of cell proliferation on ependymal cells and, in turn, the upregulation in oligodendrocyte markers in spinal cord tissue [167], thus shedding lights on the possibility of endogenous oligodendrogenesis from ependymal cells.

Since the promising findings in the origins and sources of oligoregeneration and the wealthy understandings of endogenous regulation of OPCs have been stated, is the remyelination complete? Such a speculation is cruelly diminished by postmortem examinations providing disappointing results with the presence of substantial amount of demyelinated axons especially within the center of contused spinal cord tissues [168]. And, given the difficulties with distinguishing the boarder of injury epicenter and the chronic die back of naked axons, pathological examinations focusing on the injury site alone may potentially underestimate the actual number of dysmyelinated or demyelinated axons after spinal cord trauma. Spontaneous remyelination after CNS injuries therefore remains a highly elusive phenomenon. Recruitment of OPCs into injury site relies greatly on the involvement of multiple stimulating factors, the levels of which would diminish with age [169]. Another plausible reason for insufficient remyelination after injury may be the existence of myelin sheath debris containing inhibitory molecules against OPCs differentiation such as NOGO66 via NOGO receptor complex [170]. Myelin sheaths that have survived the initial insult may also inhibit the maturation of OPCs probably by upregulating the expression of ID2 and ID4 [171]. Furthermore, glial scars formation would hinder not only the recruitment and proliferation of OPCs but also create a hostile environment for OPCs differentiation and oligodendrocytes maturation. Paradoxically, OPCs themselves may also partake in scar formation, suggesting a dual role of OPCs after SCI (see below). Taken together, it is likely that myelin sheaths repair and oligodendrocyte lineage regeneration are hindered most significantly within the epicenter of injury, whilst a more optimal site for regeneration may be found along or even at a distance from the border of the injury [13].

Bone morphogenetic proteins (BMPs) belong to the transforming growth factor- $\beta$ (TGF- $\beta$ ) super family. They act on type I and type II BMPs receptors and are important negative regulators in oligodendrocyte lineage generation [172]. Earlier evidence demonstrated that the levels of BMPs would alter after SCI [173]. Blockade of BMP4 by its extracellular antagonist, Noggin, prohibited astrogenesis and promoted the production of oligodendrocytes in OPCs culture [174]. Similarly, BMP4 was able to induce astrocyte generation and suppress oligodendrocytes production via the Smad pathways and other transcription factors [138, 173]. On the other hand, intraventricular infusion of BMP4 has been found to increase the number of OPCs during the demyelination phase. The number of OPCs significantly decreased with an increase in astrocytosis during remyelination 1 week later. Antagonism of BMP4 by Noggin could enhance remyelination and ablate the proastrogenesis effect of BMP4, suggesting that BMPs may act in a phase-specific fashion [174]. Understanding the role of BMP4 at different phases of repair is therefore of translational significance.

As mentioned above, undamaged myelin sheaths can inhibit remyelination via NOGO receptors. The latter interact with leucine-rich repeat and Ig domain-containing 1 (LINGO-1), which is a major suppressor of OPCs differentiation $[175,176]$. Attenuating LINGO-1 significantly increased the survival of oligodendrocytes and improved functional recovery after spinal cord hemisection [177]. LINGO-1 may also function as a negative regulator of neurotrophin BDNF signaling through direct interaction with $\operatorname{TrkB}$ receptors [178]. Another negative regulator is tumor necrosis factorsalpha (TNF- $\alpha)$. Both TNF- $\alpha$ and its receptor, TNF-R1, are found in OPCs. Inhibition of TNF- $\alpha$ or TNF-R1 blockade could significantly attenuate the inhibitory effects of reactive astrocytes on OPCs differentiation at the epicenter of spinal cord [179].

Generally speaking, there are two major strategies that can potentially enhance remyelination: to increase the effects of stimulating factors and to block the effects of inhibitory factors. The manipulation of a single factor alone is, however, unlikely to the necessary effects, as exemplified by the failure to enhance remyelination in transgenic mice overexpressing PDGF-A despite an increase in OPCs density [180]. Some of the factors, such as BMP4 and ZFP191, may have dual effects that materialize in a phase-specific or region-specific fashion. Therefore, therapeutic strategies targeted at endogenous remyelination need to take into considerations the impacts of different treatment time points, site of application, and, most importantly, the combined effects of different factors. Currently, the use of exogenous cell source and biomaterial scaffolds have attracted considerable research effort.

4.3. Transplantation of Oligodendrocyte Precursor Cells. A growing body of evidence has demonstrated that cellular transplantation may be of benefits. Various kinds of transplantable cells, including olfactory ensheathing cells, Schwann cells, and stem cell-derived OPCs, have been studied [181]. The current understanding is that transplanted cells would offer not so much the replacement of damaged cells but the neuroprotective and immunomodulatory effects. Herein, we will highlight a few relevant studies.

4.3.1. OPCs. Franklin et al. transplanted lac-Z-transfected O2A progenitor cells (CG4, a cell line of OPCs) into irradiated spinal cord and observed cell survival, proliferation, and migration throughout the cord [35]. They further examined the reactions of CG4 cells in an ethidium-bromide induced demyelination lesion in both irradiated and nonirradiated spinal cords. By day 15 after injury, remyelination was evident microscopically in preirradiated demyelinated lesion. Interestingly, the injected cells appeared to survive better in an injured environment than in the normal spinal cord, 
indicating that damaged axons may emit factors that promote the survivals of OPCs. Exogenous OPCs transplanted directly into the injured site seven days after injury were found to have proliferated and differentiated into oligodendrocytes but not astrocytes or neurons. Both motor function tests and electrophysiological studies confirmed neurological recovery [36]. The therapeutic effects of transgenic OPCs were further demonstrated in SCI by Rosenbluth et al. [37] and Bambakidis and Miller [38]. A summary of these pioneering studies is provided in Table 1.

These preclinical studies have provided proof of concept evidence that exogenous OPCs could enhance remyelination, but whether they can provide clinical benefit remains unknown. The availability of autologous OPCs is limited and heterologous transplantation requires the use of long-term immunosuppression that may cause serious side effects [182]. A possible alternative is human embryonic stem cells (hESCs) which are capable of differentiating into oligodendrocytes.

4.3.2. hESCs-Derived OPCs. hESCs are a potentially useful source of OPCs for clinical application [39]. They are also versatile, pluripotent "super cells" that are capable of differentiating into serotonergic [183] and dopaminergic neurons [184]. Nistor et al. described the method by which a population of OPCs with high purity and specificity could be generated from hESCs [185]. Using this technique, Keirstead et al. reported doubling of remyelinated axons one week after thoracic contusive SCI. Motor functions in the hESCs-OPCstreated group were significantly better than those in controls [40]. The same research group also demonstrated that hESCsOPCs transplantation was associated with better sparing of grey and white matter, attenuated cavitation, and altered gene expression (e.g., interleukin-10 (IL-10), hepatocyte growth factor (HGF), and Fas) in cervical spinal cord contusion [41]. In terms of somatosensory evoked potentials (SSEPs) as a surrogate of ascending pathway integrity [186], animals were found to have significant improvement in both amplitudes and latencies following transplantation [42].

These encouraging "proof-of-concept" studies have provided important evidence to support clinical trials. Recently, a company (Asterias) has obtained an approval from the US Food and Drug Administration to conduct a clinical phase I and phase II/a trial of OPCs transplantation (AST-OPC1) for SCI (NCT02302157, https://clinicaltrials.gov/). The trail is expected to commence in early 2015 and will test escalating dosages of transplanted cells and safety profile.

4.3.3. iPSCs-Derived OPCs. OPCs may also be generated from induced pluripotent stem cells (iPSCs). iPSCs-derived OPCs provide the solutions for simultaneously resolving two major hurdles within transplantation therapy, that is, the scarcity of cell source and the problem of immune-rejection. iPSCs were derived from human dermal fibroblasts in 2007 [187]. Later, by genetically reprogramming several OPCsrelated transcription factors (OLIG2, SOX10, and NKX6.2) in mouse fibroblasts cells, functional OPCs with normal morphology and oligodendrogenesis abilities were generated [188].
In 2011, Czepiel et al. succeeded in differentiating mouse iPSCs into OPCs and myelinating oligodendrocytes in vitro [44]. The majority of iPSCs-derived OPCs were found to have survived the procedure and could develop into functioning oligodendrocytes that participated in remyelination [45]. All et al. similarly transplanted iPSCs-derived OPCs into contused spinal cord and reported less cavitation together with enhanced axonal remyelination two months after treatment [46]. Perplexingly, both viable-OPCs group and Heatkilled-control group (one of the controls) showed functional improvement during the first seven days after transplantation. However, further improvement in the viable-OPCs group was not evident until the end of the first month. Notwithstanding, these studies have shown that iPSCsderived OPCs are a potentially promising and clinically accessible cell source.

Douvaras et al. have reported an interesting study in which isolated skin fibroblasts from multiple sclerosis patients were induced to form iPSCs and later OPCs. These patient-iPSCs-derived OPCs were able to initiate myelination well after being transplanted into shiverer mice with myelin deficiency [47]. The limited migratory capacity of iPSCderived OPCs derived from iPSCs could also be overcome by means of overexpressing polysialylating enzyme sialyltransferase X [48].

There are definite clinical risks associated with the use of stem cell-derived OPCs. The tumorigenicity is a major concern [189] even though no teratoma formation has so far been reported in Keirstead's serial studies [40, 41] or Geron's preclinical trial [190]. In another independent study, a total of 650 million hESCs-derived OPCs were injected, again, without any subsequent tumor-formation [43]. Another concern is that clinical and experimental SCI involve different pathological processes and that experimental models may fail to capture all critical elements found in clinical situations [191]. Whether derived OPCs are able to generate new oligodendrocytes and myelinate damaged axon is unknown. In addition, there are ethical considerations with regard to the use of human embryos that are beyond the scope of this review.

4.3.4. Other Sources of Transplantable Cells. There are other types of transplantable cells that are potentially useful for the treatment of SCI including neural stem cells [192, 193], bone marrow cells [194, 195], and Schwann cells [196, 197]. The latter are the myelin-forming cells within the peripheral nervous system. The major advantages of Schwann cells include their accessibility and immune-compatibility. Their positive roles in myelinating regenerated axons, reducing cyst formation, and improving neural functions have been extensively studied. Another candidate for therapeutic transplantation is olfactory ensheathing cells. Preclinical studies have shown that these cells could promote remyelination [198, 199], and autologous olfactory ensheathing cells are currently being studied in clinical trials with some encouraging results [199202]. In a recent study using autologous olfactory lamina propria transplantation, half of the patients with complete SCI showed some improvement in either motor or sensory functions upon long-term follow-up although the findings 


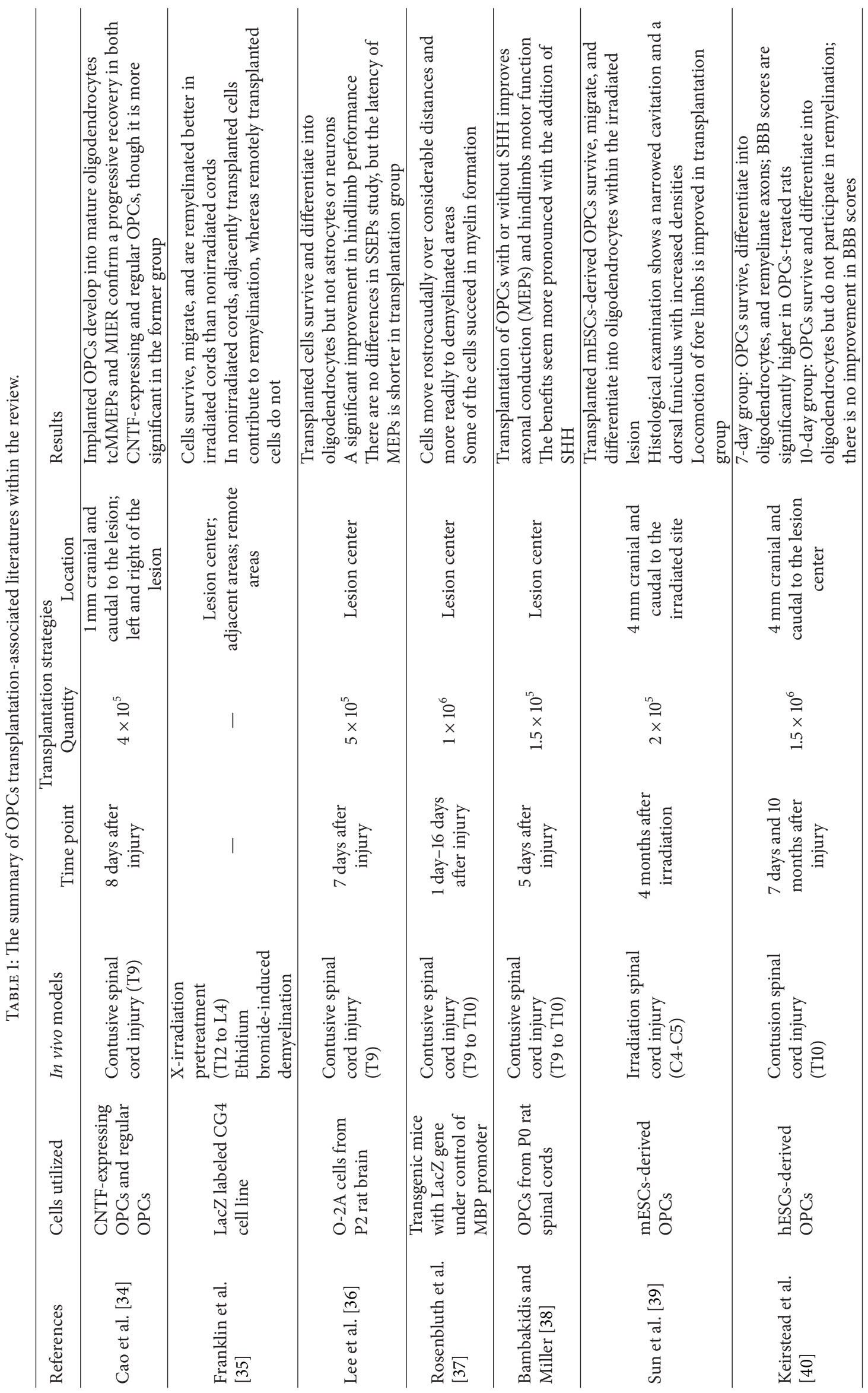




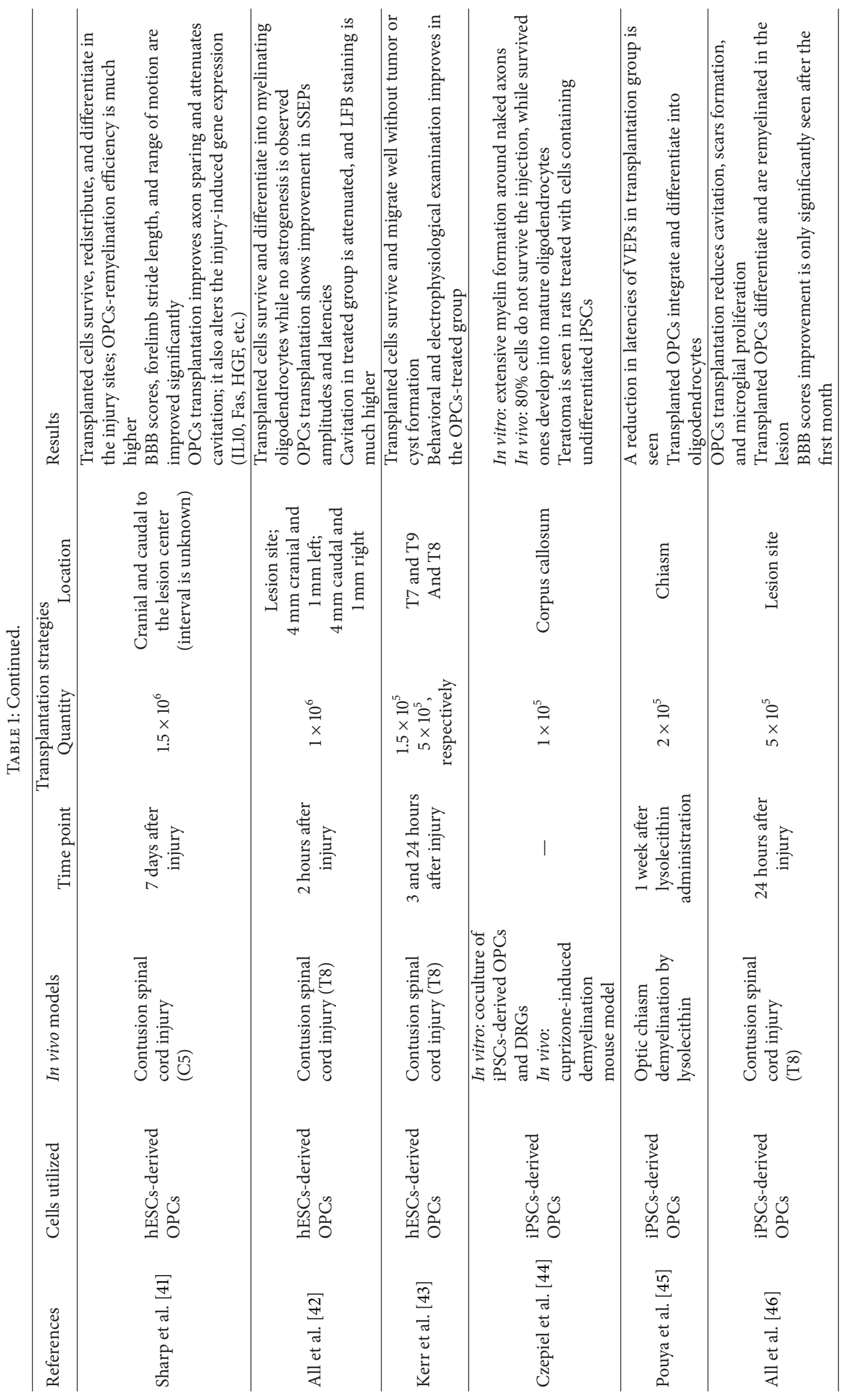




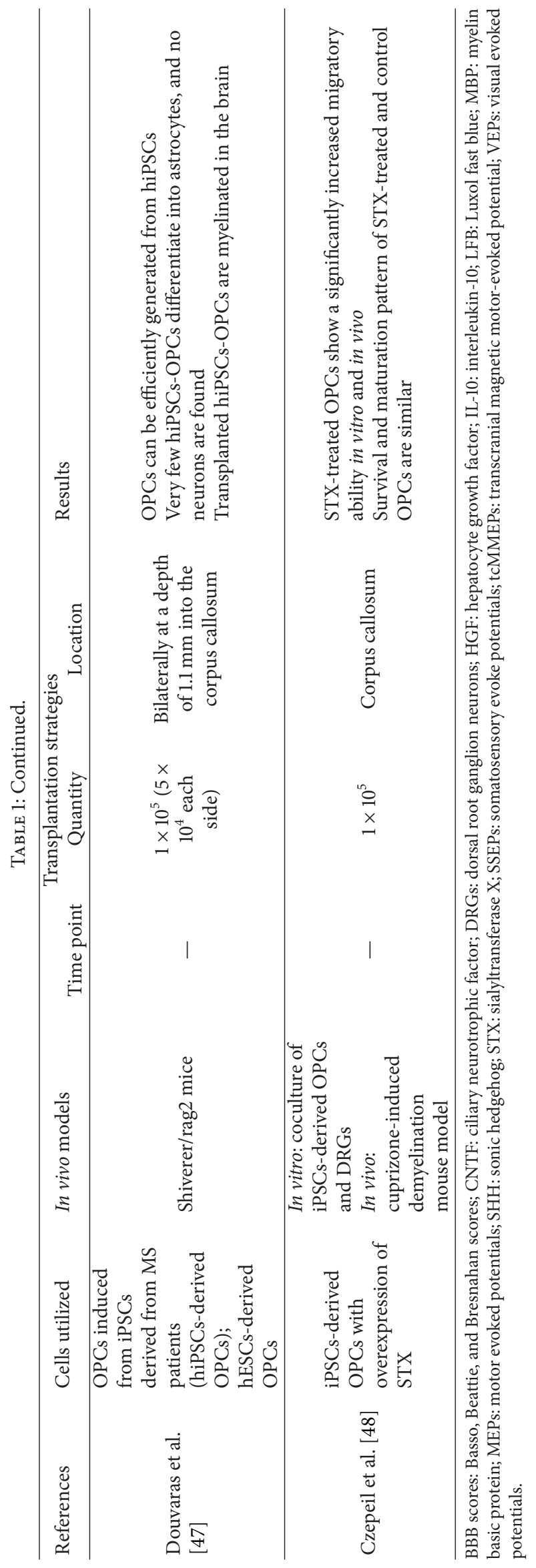


are not conclusive [203]. The authors tried to link several reasons to their results, one of which was the relatively small size of input graft when compared with the lesion size. Indecipherable enlargement of syringomyelia might also contribute to the mere recovery in this study. From our point of view, another plausible reason may be the long time span since spinal cord trauma (not less than 6 months), as it is indicated that benefits may not be witnessed when treatment is carried out after a several months-long period of time [40].

4.4. Inhibition by Oligodendrocyte Precursor Cells. Astrogliosis and glial scar formation are ubiquitous findings in SCI [204-206]. Although they serve important functions during the acute and subacute phases of injury, chronic scarring would limit axonal regeneration [207, 208]. The observation of extensive OPCs proliferation along injury boundaries also raises the question of whether these cells may in fact contribute to scarring. There are two main areas within a glial scar-the fibroblastic core and the glial surrounding zone [209]. NG2-positive cells were known to populate lesion cavities 2 days after injury, and, by day 10, these cells formed small plaques that corresponded to the glial surrounding zone. Similarly, oligodendrocytes precursors have also been identified within the fibroblastic core [210]. Hence, there is evidence to suggest that OPCs may also partake in the formation of glial scar that prohibits axonal regeneration.

Apart from being a physical barrier against regeneration, a glial scar may also act as a source of inhibitory molecules, including chondroitin sulfate proteoglycans (CSPGs), semaphorin 3, and eph/ephrin tyrosine kinases [211]. CSPGs consist of several subtypes (e.g., aggrecan, versican, NG2, neurocan, brevican, and phosphacan) and are closely linked with OPCs $[212,213]$. Amongst these, NG2 is of particular interests. Chen et al. found that growing neurites would avoid OPCs-covered areas in vitro. But when incubated with anti-NG2 antisera, these OPCs-coated membranes would attract neurite ingrowth, suggesting that NG2 may be responsible for the growth-inhibiting effect of CSPGs [214]. The underlying mechanism is incompletely understood but may involve the activations of the $\mathrm{N}$-terminal globular domain (domain 1) and the juxtamembrane domain (domain 3) of NG2 [215]. Results from subsequent in vivo studies were less clear-cut, however. de Castro et al. compared between wild-type and NG2 knockout mice and found no difference in the morphology of the transection scar. Surprisingly, calcitonin gene-related protein-positive fibers were found to grow into the scars in wild-type animals just as extensively as in NG2-null ones [216]. On the other hand, blockage of NG2 has been shown to facilitate the growth of ascending sensory axons across the caudal boundary of a lesion [217]. Similar growth-promoting effects could also be achieved by using chondroitinase ABC [218] and NG2 neutralizing antibodies [219]. There is as yet no satisfactory explanation for these controversial findings but differences in regenerating capabilities between subtypes of neurons may be responsible.

Recent studies also suggested that CSPGs might affect the formation of cellular processes by OPCs and oligodendrocytes. In an in vitro study, the presence of CSPGSs was found to reduce the length and number of processes in predifferentiated OPCs [220]. Furthermore, CSPGs could affect myelination, resulting in fewer membrane sheets that were smaller and atrophic [221]. Both Rho-Rock and protein kinase C signaling pathways [221], as well as the protein tyrosine phosphatase sigma $(\mathrm{PTP} \sigma)$ pathway [222], were thought to play important roles. Conversely, the reduction of CSPGs by xyloside was found to result in a robust increase in OPCs number as well as $\mathrm{CC} 1+$ mature oligodendrocytes in a mouse model of lysolecithin-injected spinal cord injury [223]. To further complicate the picture, different classes of CSPGs may exert different effects on OPCs [160]. Therefore, further researches are clearly needed.

\section{Conclusions}

Demyelination and oligodendrocyte loss following SCI cause significant interruption of neural functions. Current evidence supports the notion that efficient oligodendrocyte replacement and sufficient remyelination would ameliorate pathological cascades and improve neural functions. OPCs are the natural source of myelinating oligodendrocytes within the CNS following SCI. The enhancement of endogenous regeneration by innate OPCs and the transplantation of myelinating cells represent the two most promising therapeutic strategies. The elusive biological properties of OPCs and the complexity of the associated regulatory network are incompletely understood and continue to be a critical area of future investigations. A simplistic approach of targeting a single factor is unlikely to provide significant clinical benefit. The latter would necessitate a far more thorough understanding and exploitation of the complex regulatory network.

In the context of transplantation, OPCs derived from different sources may respond differently to individual growth factors and within different regions around the injury site $[97,101]$. More intriguing is the possible role of OPCs in promoting glial scar formation that may itself inhibit axonal regeneration, and it is conceivable that future discoveries may argue against the utilization of OPCs transplantation in the treatment of SCI and other demyelinating conditions. The situation is further complicated by the fact that CSPGs may in turn prohibit OPCs. Existing evidence suggests that adult OPCs contribute to CSPGs accumulation at the lesion site after injury and that premature oligodendrocytes probably do not [213]. This renders premature oligodendrocytes an attractive source of transplantable cells that are capable of generating mature oligodendrocytes without emitting CSPGs. Again, given the extremely complicated neuron-glial, glial-glial, and extracellular matrix-glial cross talks, it is unlikely that singleagent treatment would be effective; instead, combinatorial strategies targeted at oligodendrocytes lineage protection, blockage of extracellular inhibitory molecules, and myelination promotion are probably necessary.

\section{Conflict of Interests}

The authors declare no conflict of interests regarding in publication of this paper. 


\section{References}

[1] R. A. Watson and T. M. Yeung, "What is the potential of oligodendrocyte progenitor cells to successfully treat human spinal cord injury?” BMC Neurology, vol. 11, article 113, 2011.

[2] B. Lenehan, J. Street, B. K. Kwon et al., "The epidemiology of traumatic spinal cord injury in British Columbia, Canada," Spine, vol. 37, no. 4, pp. 321-329, 2012.

[3] G.-Z. Ning, Q. Wu, Y.-L. Li, and S.-Q. Feng, "Epidemiology of traumatic spinal cord injury in Asia: a systematic review," Journal of Spinal Cord Medicine, vol. 35, no. 4, pp. 229-239, 2012.

[4] M. M. P. Soldán and I. Pirko, "Biogenesis and significance of central nervous system myelin," Seminars in Neurology, vol. 32, no. 1, pp. 9-14, 2012.

[5] V. E. Miron, T. Kuhlmann, and J. P. Antel, "Cells of the oligodendroglial lineage, myelination, and remyelination," Biochimica et Biophysica Acta-Molecular Basis of Disease, vol. 1812, no. 2, pp. 184-193, 2011.

[6] S. D. Grossman, L. J. Rosenberg, and J. R. Wrathall, “Temporalspatial pattern of acute neuronal and glial loss after spinal cord contusion," Experimental Neurology, vol. 168, no. 2, pp. 273-282, 2001.

[7] J. M. Lytle and J. R. Wrathall, "Glial cell loss, proliferation and replacement in the contused murine spinal cord," European Journal of Neuroscience, vol. 25, no. 6, pp. 1711-1724, 2007.

[8] M. O. Totoiu and H. S. Keirstead, "Spinal cord injury is accompanied by chronic progressive demyelination," Journal of Comparative Neurology, vol. 486, no. 4, pp. 373-383, 2005.

[9] G. L. Li, M. Farooque, A. Holtz, and Y. Olsson, "Apoptosis of oligodendrocytes occurs for long distances away from the primary injury after compression trauma to rat spinal cord," Acta Neuropathologica, vol. 98, no. 5, pp. 473-480, 1999.

[10] A. Delshad and T. Al-Tiraihi, "Ultrastructure of apoptotic oligodendrocytes in the spinal cord of adult rat with longstanding axotomised sciatic nerve," Folia Neuropathologica, vol. 39, no. 3, pp. 125-128, 2001.

[11] T. Takagi, M. Takayasu, M. Mizuno, M. Yoshimoto, and J. Yoshida, "Caspase activation in neuronal and glial apoptosis following spinal cord injury in mice," Neurologia MedicoChirurgica, vol. 43, no. 1, pp. 20-29, 2003.

[12] A. Almad, F. R. Sahinkaya, and D. M. McTigue, "Oligodendrocyte fate after spinal cord injury," Neurotherapeutics, vol. 8, no. 2, pp. 262-273, 2011.

[13] J. R. Plemel, M. B. Keough, G. J. Duncan et al., "Remyelination after spinal cord injury: is it a target for repair?" Progress in Neurobiology, vol. 117, pp. 54-72, 2014.

[14] H. Kanno, H. Ozawa, A. Sekiguchi, S. Yamaya, and E. Itoi, "Induction of autophagy and autophagic cell death in damaged neural tissue after acute spinal cord injury in mice," Spine, vol. 36, no. 22, pp. E1427-E1434, 2011.

[15] H. Kanno, H. Ozawa, A. Sekiguchi, and E. Itoi, "Spinal cord injury induces upregulation of Beclin 1 and promotes autophagic cell death," Neurobiology of Disease, vol. 33, no. 2, pp. 143-148, 2009.

[16] C. M. Smith, J. A. Mayer, and I. D. Duncan, "Autophagy promotes oligodendrocyte survival and function following dysmyelination in a long-lived myelin mutant," The Journal of Neuroscience, vol. 33, no. 18, pp. 8088-8100, 2013.
[17] I. R. Griffiths and M. C. McCulloch, "Nerve fibres in spinal cord impact injuries. Part 1. Changes in the myelin sheath during the initial 5 weeks," Journal of the Neurological Sciences, vol. 58, no. 3, pp. 335-349, 1983.

[18] K. M. Young, K. Psachoulia, R. B. Tripathi et al., "Oligodendrocyte dynamics in the healthy adult CNS: evidence for myelin remodeling," Neuron, vol. 77, no. 5, pp. 873-885, 2013.

[19] S. Y. C. Chong, S. S. Rosenberg, S. P. J. Fancy et al., "Neurite outgrowth inhibitor Nogo-A establishes spatial segregation and extent of oligodendrocyte myelination," Proceedings of the National Academy of Sciences of the United States of America, vol. 109, no. 4, pp. 1299-1304, 2012.

[20] I. Griffiths, M. Klugmann, T. Anderson et al., "Axonal swellings and degeneration in mice lacking the major proteolipid of myelin," Science, vol. 280, no. 5369, pp. 1610-1613, 1998.

[21] C. Lappe-Siefke, S. Goebbels, M. Gravel et al., "Disruption of Cnp1 uncouples oligodendroglial functions in axonal support and myelination," Nature Genetics, vol. 33, no. 3, pp. 366-374, 2003.

[22] T. Nguyen, N. R. Mehta, K. Conant et al., "Axonal protective effects of the myelin-associated glycoprotein," The Journal of Neuroscience, vol. 29, no. 3, pp. 630-637, 2009.

[23] M. Tanaka, T. Izawa, J. Yamate et al., "The VF rat with abnormal myelinogenesis has a mutation in Dopey1," Glia, vol. 62, no. 9, pp. 1530-1542, 2014.

[24] K.-A. Nave, "Myelination and the trophic support of long axons," Nature Reviews Neuroscience, vol. 11, no. 4, pp. 275-283, 2010.

[25] S. B. Tekkök, A. M. Brown, R. Westenbroek, L. Pellerin, and B. R. Ransom, "Transfer of glycogen-derived lactate from astrocytes to axons via specific monocarboxylate transporters supports mouse optic nerve activity," Journal of Neuroscience Research, vol. 81, no. 5, pp. 644-652, 2005.

[26] U. Fünfschilling, L. M. Supplie, D. Mahad et al., "Glycolytic oligodendrocytes maintain myelin and long-term axonal integrity," Nature, vol. 485, no. 7399, pp. 517-521, 2012.

[27] S. Baltan, "Can lactate serve as an energy substrate for axons in good times and in bad, in sickness and in health?" Metabolic Brain Disease, vol. 30, no. 1, pp. 25-30, 2015.

[28] Y. Lee, B. M. Morrison, Y. Li et al., "Oligodendroglia metabolically support axons and contribute to neurodegeneration," Nature, vol. 487, no. 7408, pp. 443-448, 2012.

[29] E. Adriano, L. Perasso, I. Panfoli et al., "A novel hypothesis about mechanisms affecting conduction velocity of central myelinated fibers," Neurochemical Research, vol. 36, no. 10, pp. 1732-1739, 2011.

[30] S. Ravera, M. Bartolucci, E. Adriano et al., "Support of nerve conduction by respiring myelin sheath: role of connexons," Molecular Neurobiology, 2015.

[31] A. Morelli, S. Ravera, and I. Panfoli, "Hypothesis of an energetic function for myelin," Cell Biochemistry and Biophysics, vol. 61, no. 1, pp. 179-187, 2011.

[32] J. M. Edgar, M. McLaughlin, H. B. Werner et al., "Early ultrastructural defects of axons and axon-glia junctions in mice lacking expression of Cnpl," GLIA, vol. 57, no. 16, pp. 1815-1824, 2009.

[33] C. M. Kassmann, C. Lappe-Siefke, M. Baes et al., "Axonal loss and neuroinflammation caused by peroxisome-deficient 
oligodendrocytes," Nature Genetics, vol. 39, no. 8, pp. 969-976, 2007.

[34] Q. Cao, Q. He, Y. Wang et al., "Transplantation of ciliary neurotrophic factor-expressing adult oligodendrocyte precursor cells promotes remyelination and functional recovery after spinal cord injury," Journal of Neuroscience, vol. 30, no. 8, pp. 2989-3001, 2010.

[35] R. J. M. Franklin, S. A. Bayley, and W. F. Blakemore, "Transplanted CG4 cells (an oligodendrocyte progenitor cell line) survive, migrate, and contribute to repair of areas of demyelination in X-irradiated and damaged spinal cord but not in normal spinal cord," Experimental Neurology, vol. 137, no. 2, pp. 263276, 1996.

[36] K. H. Lee, D. H. Yoon, Y. G. Park, and B. H. Lee, "Effects of glial transplantation on functional recovery following acute spinal cord injury," Journal of Neurotrauma, vol. 22, no. 5, pp. 575-589, 2005.

[37] J. Rosenbluth, R. Schiff, W.-L. Liang, G. Menna, and W. Young, "Xenotransplantation of transgenic oligodendrocytelineage cells into spinal cord-injured adult rats," Experimental Neurology, vol. 147, no. 1, pp. 172-182, 1997.

[38] N. C. Bambakidis and R. H. Miller, "Transplantation of oligodendrocyte precursors and sonic hedgehog results in improved function and white matter sparing in the spinal cords of adult rats after contusion," Spine Journal, vol. 4, no. 1, pp. 16-26, 2004.

[39] Y. Sun, C.-C. Xu, J. Li et al., “Transplantation of oligodendrocyte precursor cells improves locomotion deficits in rats with spinal cord irradiation injury," PLoS ONE, vol. 8, no. 2, Article ID e57534, 2013.

[40] H. S. Keirstead, G. Nistor, G. Bernal et al., "Human embryonic stem cell-derived oligodendrocyte progenitor cell transplants remyelinate and restore locomotion after spinal cord injury," Journal of Neuroscience, vol. 25, no. 19, pp. 4694-4705, 2005.

[41] J. Sharp, J. Frame, M. Siegenthaler, G. Nistor, and H. S. Keirstead, "Human embryonic stem cell-derived oligodendrocyte progenitor cell transplants improve recovery after cervical spinal cord injury," Stem Cells, vol. 28, no. 1, pp. 152-163, 2010.

[42] A. H. All, F. A. Bazley, S. Gupta et al., "Human embryonic stem cell-derived oligodendrocyte progenitors aid in functional recovery of sensory pathways following contusive spinal cord injury," PLoS ONE, vol. 7, no. 10, Article ID e47645, 2012.

[43] C. L. Kerr, B. S. Letzen, C. M. Hill et al., "Efficient differentiation of human embryonic stem cells into oligodendrocyte progenitors for application in a rat contusion model of spinal cord injury," International Journal of Neuroscience, vol. 120, no. 4, pp. 305-313, 2010.

[44] M. Czepiel, V. Balasubramaniyan, W. Schaafsma et al., "Differentiation of induced pluripotent stem cells into functional oligodendrocytes," Glia, vol. 59, no. 6, pp. 882-892, 2011.

[45] A. Pouya, L. Satarian, S. Kiani, M. Javan, and H. Baharvand, "Human induced pluripotent stem cells differentiation into oligodendrocyte progenitors and transplantation in a rat model of optic chiasm demyelination," PLoS ONE, vol. 6, no. 11, Article ID e27925, 2011.

[46] A. H. All, P. Gharibani, S. Gupta et al., "Early intervention for spinal cord injury with human induced pluripotent stem cells oligodendrocyte progenitors," PLoS ONE, vol. 10, no. 1, Article ID e0116933, 2015.
[47] P. Douvaras, J. Wang, M. Zimmer et al., "Efficient generation of myelinating oligodendrocytes from primary progressive multiple sclerosis patients by induced pluripotent stem cells," Stem Cell Reports, vol. 3, no. 2, pp. 250-259, 2014.

[48] M. Czepiel, L. Leicher, K. Becker, E. Boddeke, and S. Copray, "Overexpression of polysialylated neural cell adhesion molecule improves the migration capacity of induced pluripotent stem cell-derived oligodendrocyte precursors," Stem Cells Translational Medicine, vol. 3, no. 9, pp. 1100-1109, 2014.

[49] J. E. Vaughn and A. Peters, "A third neuroglial cell type. An electron microscopic study," Journal of Comparative Neurology, vol. 133, no. 2, pp. 269-288, 1968.

[50] R. P. Skoff and J. E. Vaughn, "An autoradiographic study of cellular proliferation in degenerating rat optic nerve," Journal of Comparative Neurology, vol. 141, no. 2, pp. 133-155, 1971.

[51] J. E. Vaughn, P. L. Hinds, and R. P. Skoff, "Electron microscopic studies of Wallerian degeneration in rat optic nerves. I. The multipotential glia," Journal of Comparative Neurology, vol. 140, no. 2, pp. 175-206, 1970.

[52] M. C. Raff, R. H. Miller, and M. Noble, "A glial progenitor cell that develops in vitro into an astrocyte or an oligodendrocyte depending on culture medium," Nature, vol. 303, no. 5916, pp. 390-396, 1983.

[53] C. Ffrench-Constant and M. C. Raff, "Proliferating bipotential glial progenitor cells in adult rat optic nerve," Nature, vol. 319, no. 6053, pp. 499-502, 1986.

[54] J. Shi, A. Marinovich, and B. A. Barres, "Purification and characterization of adult oligodendrocyte precursor cells from the rat optic nerve," The Journal of Neuroscience, vol. 18, no. 12, pp. 4627-4636, 1998.

[55] J. M. Levine, R. Reynolds, and J. W. Fawcett, "The oligodendrocyte precursor cell in health and disease," Trends in Neurosciences, vol. 24, no. 1, pp. 39-47, 2001.

[56] M. R. L. Dawson, A. Polito, J. M. Levine, and R. Reynolds, "NG2-expressing glial progenitor cells: an abundant and widespread population of cycling cells in the adult rat CNS," Molecular and Cellular Neuroscience, vol. 24, no. 2, pp. 476-488, 2003.

[57] Y. Chen, V. Balasubramaniyan, J. Peng et al., "Isolation and culture of rat and mouse oligodendrocyte precursor cells," Nature Protocols, vol. 2, no. 5, pp. 1044-1051, 2007.

[58] T. Kondo and M. Raff, "Oligodendrocyte precursor cells reprogrammed to become multipotential CNS stem cells," Science, vol. 289, no. 5485, pp. 1754-1757, 2000.

[59] G. Vogel, "Developmental biology: brain cells turning over a new leaf," Science, vol. 289, no. 5485, Article ID 1666a, 2000.

[60] S. Belachew, R. Chittajallu, A. A. Aguirre et al., "Postnatal NG2 proteoglycan-expressing progenitor cells are intrinsically multipotent and generate functional neurons," Journal of Cell Biology, vol. 161, no. 1, pp. 169-186, 2003.

[61] M. C. Nunes, N. S. Roy, H. M. Keyoung et al., "Identification and isolation of multipotential neural progenitor cells from the subcortical white matter of the adult human brain," Nature Medicine, vol. 9, no. 4, pp. 439-447, 2003.

[62] F. Guo, Y. Maeda, J. Ma et al., "Pyramidal neurons are generated from oligodendroglial progenitor cells in adult piriform cortex," Journal of Neuroscience, vol. 30, no. 36, pp. 12036-12049, 2010. 
[63] L. E. Rivers, K. M. Young, M. Rizzi et al., "PDGFRA/NG2 glia generate myelinating oligodendrocytes and piriform projection neurons in adult mice," Nature Neuroscience, vol. 11, no. 12, pp. 1392-1401, 2008.

[64] Y. Tamura, Y. Kataoka, Y. Cui, Y. Takamori, Y. Watanabe, and H. Yamada, "Multi-directional differentiation of doublecortinand NG2-immunopositive progenitor cells in the adult rat neocortex in vivo," European Journal of Neuroscience, vol. 25, no. 12, pp. 3489-3498, 2007.

[65] F. Guo, J. Ma, E. McCauley, P. Bannerman, and D. Pleasure, "Early postnatal proteolipid promoter-expressing progenitors produce multilineage cells in vivo," The Journal of Neuroscience, vol. 29, no. 22, pp. 7256-7270, 2009.

[66] D. E. Bergles, J. D. B. Roberts, P. Somogyl, and C. E. Jahr, "Glutamatergic synapses on oligodendrocyte precursor cells in the hippocampus," Nature, vol. 405, no. 6783, pp. 187-191, 2000.

[67] J. L. Ziskin, A. Nishiyama, M. Rubio, M. Fukaya, and D. E. Bergles, "Vesicular release of glutamate from unmyelinated axons in white matter," Nature Neuroscience, vol. 10, no. 3, pp. 321-330, 2007.

[68] M. Kukley, E. Capetillo-Zarate, and D. Dietrich, "Vesicular glutamate release from axons in white matter," Nature Neuroscience, vol. 10, no. 3, pp. 311-320, 2007.

[69] C. Li, L. Xiao, X. Liu et al., "A functional role of NMDA receptor in regulating the differentiation of oligodendrocyte precursor cells and remyelination," Glia, vol. 61, no. 5, pp. 732-749, 2013.

[70] L. Xiao, C. Hu, W. Yang et al., "NMDA receptor couples RaclGEF Tiam1 to direct oligodendrocyte precursor cell migration," Glia, vol. 61, no. 12, pp. 2078-2099, 2013.

[71] J.-M. Mangin and V. Gallo, "The curious case of NG2 cells: transient trend or game changer?" ASN Neuro, vol. 3, no. 1, Article ID e00052, 2011.

[72] J. Fannon, W. Tarmier, and D. Fulton, "Neuronal activity and AMPA-type glutamate receptor activation regulates the morphological development of oligodendrocyte precursor cells," Glia, vol. 63, no. 6, pp. 1021-1035, 2015.

[73] A. Sahel, F. C. Ortiz, C. Kerninon, P. P. Maldonado, M. C. Angulo, and B. Nait-Oumesmar, "Alteration of synaptic connectivity of oligodendrocyte precursor cells following demyelination," Frontiers in Cellular Neuroscience, vol. 9, article 77, 2015.

[74] M. Velez-Fort, P. P. Maldonado, A. M. Butt, E. Audinat, and M. C. Angulo, "Postnatal switch from synaptic to extrasynaptic transmission between interneurons and NG2 cells," The Journal of Neuroscience, vol. 30, no. 20, pp. 6921-6929, 2010.

[75] S.-C. Lin and D. E. Bergles, "Synaptic signaling between GABAergic interneurons and oligodendrocyte precursor cells in the hippocampus," Nature Neuroscience, vol. 7, no. 1, pp. 2432, 2004.

[76] A. Pastor, A. Chvatal, E. Sykova, and H. Kettenmann, "Glycineand GABA-activated currents in identified glial cells of the developing rat spinal cord slice," European Journal of Neuroscience, vol. 7, no. 6, pp. 1188-1198, 1995.

[77] X. P. Tong, X. Y. Li, B. Zhou et al., " $\mathrm{Ca}^{2+}$ signaling evoked by activation of $\mathrm{Na}^{+}$channels and $\mathrm{Na}^{+} / \mathrm{Ca}^{2+}$ exchangers is required for GABA-induced NG2 cell migration," The Journal of Cell Biology, vol. 186, no. 1, pp. 113-128, 2009.

[78] N. Fröhlich, B. Nagy, A. Hovhannisyan, and M. Kukley, "Fate of neuron-glia synapses during proliferation and differentiation of NG2 cells," Journal of Anatomy, vol. 219, no. 1, pp. 18-32, 2011.
[79] M. Zonouzi, J. Scafidi, P. Li et al., "GABAergic regulation of cerebellar NG2 cell development is altered in perinatal white matter injury," Nature Neuroscience, vol. 18, no. 5, pp. 674-682, 2015.

[80] K. Luyt, T. P. Slade, J. J. Dorward et al., "Developing oligodendrocytes express functional $\mathrm{GABA}(\mathrm{B})$ receptors that stimulate cell proliferation and migration," Journal of Neurochemistry, vol. 100, no. 3, pp. 822-840, 2007.

[81] B. Stevens, S. Porta, L. L. Haak, V. Gallo, and R. D. Fields, "Adenosine: a neuron-glial transmitter promoting myelination in the CNS in response to action potentials," Neuron, vol. 36, no. 5, pp. 855-868, 2002.

[82] T. Othman, H. Yan, and S. A. Rivkees, "Oligodendrocytes express functional A1 adenosine receptors that stimulate cellular migration," Glia, vol. 44, no. 2, pp. 166-172, 2003.

[83] E. Coppi, L. Cellai, G. Maraula, A. M. Pugliese, and F. Pedata, "Adenosine $\mathrm{A}_{2 \mathrm{~A}}$ receptors inhibit delayed rectifier potassium currents and cell differentiation in primary purified oligodendrocyte cultures," Neuropharmacology, vol. 73, pp. 301-310, 2013.

[84] E. González-Fernández, M. V. Sánchez-Gómez, A. PérezSamartín, R. O. Arellano, and C. Matute, "A3 adenosine receptors mediate oligodendrocyte death and ischemic damage to optic nerve," Glia, vol. 62, no. 2, pp. 199-216, 2014.

[85] C. Agresti, M. E. Meomartini, S. Amadio et al., "ATP regulates oligodendrocyte progenitor migration, proliferation, and differentiation: involvement of metabotropic P2 receptors," Brain Research Reviews, vol. 48, no. 2, pp. 157-165, 2005.

[86] C. Matute, I. Torre, F. Pérez-Cerdá et al., "P2X(7) receptor blockade prevents ATP excitotoxicity in oligodendrocytes and ameliorates experimental autoimmune encephalomyelitis," The Journal of Neuroscience, vol. 27, no. 35, pp. 9525-9533, 2007.

[87] L.-Y. Wang, W.-Q. Cai, P.-H. Chen, Q.-Y. Deng, and C.-M. Zhao, "Downregulation of $\mathrm{P}_{2} \mathrm{X}_{7}$ receptor expression in rat oligodendrocyte precursor cells after hypoxia ischemia," Glia, vol. 57, no. 3, pp. 307-319, 2009.

[88] C. Agresti, M. E. Meomartini, S. Amadio et al., "Metabotropic P2 receptor activation regulates oligodendrocyte progenitor migration and development," Glia, vol. 50, no. 2, pp. 132-144, 2005.

[89] J. T. Laitinen, A. Uri, G. Raidaru, and R. Miettinen, "[(35)S]GTPgammaS autoradiography reveals a wide distribution of Gi/o-linked ADP receptors in the nervous system: close similarities with the platelet P2YADP receptor," Journal of Neurochemistry, vol. 77, no. 2, pp. 505-518, 2001.

[90] S. Amadio, G. Tramini, A. Martorana et al., "Oligodendrocytes express P2Y12 metabotropic receptor in adult rat brain," Neuroscience, vol. 141, no. 3, pp. 1171-1180, 2006.

[91] J. N. Larocca and G. Almazan, "Acetylcholine agonists stimulate mitogen-activated protein kinase in oligodendrocyte progenitors by muscarinic receptors," Journal of Neuroscience Research, vol. 50, no. 5, pp. 743-754, 1997.

[92] Q.-L. Cui, E. Fogle, and G. Almazan, "Muscarinic acetylcholine receptors mediate oligodendrocyte progenitor survival through Src-like tyrosine kinases and PI3K/Akt pathways," Neurochemistry International, vol. 48, no. 5, pp. 383-393, 2006.

[93] F. De Angelis, A. Bernardo, V. Magnaghi, L. Minghetti, and A. M. Tata, "Muscarinic receptor subtypes as potential targets to modulate oligodendrocyte progenitor survival, proliferation, 
and differentiation," Developmental Neurobiology, vol. 72, no. 5, pp. 713-728, 2012.

[94] K. Abiraman, S. U. Pol, M. A. O’Bara et al., "Anti-muscarinic adjunct therapy accelerates functional human oligodendrocyte repair," Journal of Neuroscience, vol. 35, no. 8, pp. 3676-3688, 2015.

[95] M. Vélez-Fort, E. Audinat, and M. C. Angulo, "Functional alpha 7-containing nicotinic receptors of NG2-expressing cells in the hippocampus," Glia, vol. 57, no. 10, pp. 1104-1114, 2009.

[96] S. W. Rogers, N. Z. Gregori, N. Carlson, L. C. Gahring, and M. Noble, "Neuronal nicotinic acetylcholine receptor expression by O2A/Oligodendrocyte progenitor cells," Glia, vol. 33, no. 4, pp. 306-313, 2001.

[97] R. A. Hill, K. D. Patel, J. Medved, A. M. Reiss, and A. Nishiyama, "NG2 cells in white matter but not gray matter proliferate in response to PDGF," Journal of Neuroscience, vol. 33, no. 36, pp. 14558-14566, 2013.

[98] E. E. Frost, Z. Zhou, K. Krasnesky, and R. C. Armstrong, "Initiation of oligodendrocyte progenitor cell migration by a PDGF-A activated extracellular regulated kinase (ERK) signaling pathway," Neurochemical Research, vol. 34, no. 1, pp. 169-181, 2009.

[99] K. Azim, O. Raineteau, and A. M. Butt, "Intraventricular injection of FGF-2 promotes generation of oligodendrocytelineage cells in the postnatal and adult forebrain," Glia, vol. 60, no. 12, pp. 1977-1990, 2012.

[100] M. Furusho, A. J. Roulois, R. J. Franklin, and R. Bansal, "Fibroblast growth factor signaling in oligodendrocyte-lineage cells facilitates recovery of chronically demyelinated lesions but is redundant in acute lesions," Glia, 2015.

[101] J.-G. Hu, X.-J. Wu, Y.-F. Feng et al., "PDGF-AA and bFGF mediate B104CM-induced proliferation of oligodendrocyte precursor cells," International Journal of Molecular Medicine, vol. 30, no. 5, pp. 1113-1118, 2012.

[102] J. F. Talbott, Q. Cao, J. Bertram et al., "CNTF promotes the survival and differentiation of adult spinal cord-derived oligodendrocyte precursor cells in vitro but fails to promote remyelination in vivo," Experimental Neurology, vol. 204, no. 1, pp. 485-489, 2007.

[103] J. Vernerey, M. Macchi, K. Magalon, M. Cayre, and P. Durbec, "Ciliary neurotrophic factor controls progenitor migration during remyelination in the adult rodent brain," The Journal of Neuroscience, vol. 33, no. 7, pp. 3240-3250, 2013.

[104] R. B. Tripathi and D. M. McTigue, "Chronically increased ciliary neurotrophic factor and fibroblast growth factor-2 expression after spinal contusion in rats," Journal of Comparative Neurology, vol. 510, no. 2, pp. 129-144, 2008.

[105] J. Xiao, A. W. Wong, M. M. Willingham, M. van den Buuse, T. J. Kilpatrick, and S. S. Murray, "Brain-derived neurotrophic factor promotes central nervous system myelination via a direct effect upon oligodendrocytes," NeuroSignals, vol. 18, no. 3, pp. 186202, 2010.

[106] A. W. Wong, J. Xiao, D. Kemper, T. J. Kilpatrick, and S. S. Murray, "Oligodendroglial expression of TrkB independently regulates myelination and progenitor cell proliferation," The Journal of Neuroscience, vol. 33, no. 11, pp. 4947-4957, 2013.

[107] B. A. Barres and M. C. Raff, "Control of oligodendrocyte number in the developing rat optic nerve," Neuron, vol. 12, no. 5, pp. 935-942, 1994.
[108] H.-T. Zhang, Z.-Y. Gao, Y.-Z. Chen, and T.-H. Wang, “Temporal changes in the level of neurotrophins in the spinal cord and associated precentral gyrus following spinal hemisection in adult Rhesus monkeys," Journal of Chemical Neuroanatomy, vol. 36, no. 3-4, pp. 138-143, 2008.

[109] X.-L. Li, W. Zhang, X. Zhou et al., "Temporal changes in the expression of some neurotrophins in spinal cord transected adult rats," Neuropeptides, vol. 41, no. 3, pp. 135-143, 2007.

[110] A. M. Thomas, S. K. Seidlits, A. G. Goodman et al., "Sonic hedgehog and neurotrophin-3 increase oligodendrocyte numbers and myelination after spinal cord injury," Integrative Biology, vol. 6, no. 7, pp. 694-705, 2014.

[111] G. Banisadr, R.-D. Gosselin, P. Mechighel, W. Rostène, P. Kitabgi, and S. M. Parsadaniantz, "Constitutive neuronal expression of CCR2 chemokine receptor and its colocalization with neurotransmitters in normal rat brain: functional effect of MCP-1/CCL2 on calcium mobilization in primary cultured neurons," Journal of Comparative Neurology, vol. 492, no. 2, pp. 178-192, 2005.

[112] M. W. Adler, E. B. Geller, X. Chen, and T. J. Rogers, "Viewing chemokines as a third major system of communication in the brain," AAPS Journal, vol. 7, no. 4, pp. E865-E870, 2005.

[113] X. Zhang, C. Chen, S. Ma, Y. Wang, X. Zhang, and X. Su, "Inhibition of monocyte chemoattractant peptide-1 decreases secondary spinal cord injury," Molecular Medicine Reports, vol. 11, no. 6, pp. 4262-4266, 2015.

[114] L. Kadi, R. Selvaraju, P. de Lys, A. E. I. Proudfoot, T. N. C. Wells, and U. Boschert, "Differential effects of chemokines on oligodendrocyte precursor proliferation and myelin formation in vitro," Journal of Neuroimmunology, vol. 174, no. 1-2, pp. 133146, 2006.

[115] J. R. Patel, J. L. Williams, M. M. Muccigrosso et al., "Astrocyte TNFR2 is required for CXCL12-mediated regulation of oligodendrocyte progenitor proliferation and differentiation within the adult CNS," Acta Neuropathologica, vol. 124, no. 6, pp. 847860, 2012.

[116] G. Banisadr, T. J. Frederick, C. Freitag et al., "The role of CXCR4 signaling in the migration of transplanted oligodendrocyte progenitors into the cerebral white matter," Neurobiology of Disease, vol. 44, no. 1, pp. 19-27, 2011.

[117] E. Tirotta, L. A. Kirby, M. N. Hatch, and T. E. Lane, "IFN- $\gamma$ induced apoptosis of human embryonic stem cell derived oligodendrocyte progenitor cells is restricted by CXCR2 signaling," Stem Cell Research, vol. 9, no. 3, pp. 208-217, 2012.

[118] E. Tirotta, R. M. Ransohoff, and T. E. Lane, "CXCR2 signaling protects oligodendrocyte progenitor cells from IFN- $\gamma /$ CXCL10mediated apoptosis," Glia, vol. 59, no. 10, pp. 1518-1528, 2011.

[119] I. Pineau and S. Lacroix, "Proinflammatory cytokine synthesis in the injured mouse spinal cord: multiphasic expression pattern and identification of the cell types involved," Journal of Comparative Neurology, vol. 500, no. 2, pp. 267-285, 2007.

[120] T. Ishibashi, P. R. Lee, H. Baba, and R. D. Fields, "Leukemia inhibitory factor regulates the timing of oligodendrocyte development and myelination in the postnatal optic nerve," Journal of Neuroscience Research, vol. 87, no. 15, pp. 3343-3355, 2009.

[121] S. Rittchen, A. Boyd, A. Burns et al., "Myelin repair in vivo is increased by targeting oligodendrocyte precursor cells with nanoparticles encapsulating leukaemia inhibitory factor (LIF)," Biomaterials, vol. 56, pp. 78-85, 2015. 
[122] D. D. Rowe, L. A. Collier, H. A. Seifert et al., "Leukemia inhibitor factor promotes functional recovery and oligodendrocyte survival in rat models of focal ischemia," European Journal of Neuroscience, vol. 40, no. 7, pp. 3111-3119, 2014.

[123] W. Pan and A. J. Kastin, "Cytokine transport across the injured blood-spinal cord barrier," Current Pharmaceutical Design, vol. 14, no. 16, pp. 1620-1624, 2008.

[124] L.-J. Chew, W. C. King, A. Kennedy, and V. Gallo, "Interferongamma inhibits cell cycle exit in differentiating oligodendrocyte progenitor cells," Glia, vol. 52, no. 2, pp. 127-143, 2005.

[125] J. M. Rodgers, A. P. Robinson, E. S. Rosler et al., "IL-17A activates ERK1/2 and enhances differentiation of oligodendrocyte progenitor cells," Glia, vol. 63, no. 5, pp. 768-779, 2015.

[126] J. M. Vela, E. Molina-Holgado, Á. Arévalo-Martín, G. Almazán, and C. Guaza, "Interleukin-1 regulates proliferation and differentiation of oligodendrocyte progenitor cells," Molecular and Cellular Neuroscience, vol. 20, no. 3, pp. 489-502, 2002.

[127] Q. R. Lu, D.-I. Yuk, J. A. Alberta et al., "Sonic hedgehogregulated oligodendrocyte lineage genes encoding bHLH proteins in the mammalian central nervous system," Neuron, vol. 25 , no. 2 , pp. $317-329,2000$.

[128] Q. Zhou, S. Wang, and D. J. Anderson, "Identification of a novel family of oligodendrocyte lineage-specific basic helixloop-helix transcription factors," Neuron, vol. 25, no. 2, pp. 331$343,2000$.

[129] Q. Zhou and D. J. Anderson, “The bHLH transcription factors OLIG2 and OLIG1 couple neuronal and glial subtype specification," Cell, vol. 109, no. 1, pp. 61-73, 2002.

[130] V. Balasubramaniyan, N. Timmer, B. Kust, E. Boddeke, and S. Copray, "Transient expression of Olig1 initiates the differentiation of neural stem cells into oligodendrocyte progenitor cells," Stem Cells, vol. 22, no. 6, pp. 878-882, 2004.

[131] C. L. Maire, A. Wegener, C. Kerninon, and B. N. Oumesmar, "Gain-of-function of Olig transcription factors enhances oligodendrogenesis and myelination," Stem Cells, vol. 28, no. 9, pp. 1611-1622, 2010.

[132] S. Copray, V. Balasubramaniyan, J. Levenga, J. de Bruijn, R. Liem, and E. Boddeke, "Olig2 overexpression induces the in vitro differentiation of neural stem cells into mature oligodendrocytes," Stem Cells, vol. 24, no. 4, pp. 1001-1010, 2006.

[133] Z. Liu, X. Hu, J. Cai et al., "Induction of oligodendrocyte differentiation by Olig2 and Sox10: evidence for reciprocal interactions and dosage-dependent mechanisms," Developmental Biology, vol. 302, no. 2, pp. 683-693, 2007.

[134] A. Wegener, C. Deboux, C. Bachelin et al., "Gain of Olig2 function in oligodendrocyte progenitors promotes remyelination," Brain, vol. 138, no. 1, pp. 120-135, 2015.

[135] C. Zhang, G. Zhang, W. Rong, A. Wang, C. Wu, and X. Huo, "Oscillating field stimulation promotes spinal cord remyelination by inducing differentiation of oligodendrocyte precursor cells after spinal cord injury," Bio-Medical Materials and Engineering, vol. 24, no. 6, pp. 3629-3636, 2014.

[136] H. M. Kim, D. H. Hwang, J. Y. Choi et al., "Differential and cooperative actions of Olig1 and Olig2 transcription factors on immature proliferating cells after contusive spinal cord injury," Glia, vol. 59, no. 7, pp. 1094-1106, 2011.

[137] J. Paes de Faria, N. Kessaris, P. Andrew, W. D. Richardson, and H. Li, "New Olig1 null mice confirm a non-essential role for
Olig1 in oligodendrocyte development," BMC Neuroscience, vol. 15, article 12, 2014.

[138] X. Cheng, Y. Wang, Q. He, M. Qiu, S. R. Whittemore, and Q. Cao, "Bone morphogenetic protein signaling and olig1/2 interact to regulate the differentiation and maturation of adult oligodendrocyte precursor cells," Stem Cells, vol. 25, no. 12, pp. 3204-3214, 2007.

[139] S.-Q. Huang, C.-L. Tang, S.-Q. Sun et al., "Demyelination initiated by oligodendrocyte apoptosis through enhancing endoplasmic reticulum-mitochondria interactions and Id2 expression after compressed spinal cord injury in rats," CNS Neuroscience and Therapeutics, vol. 20, no. 1, pp. 20-31, 2014.

[140] S. Huang, C. Tang, S. Sun et al., "Protective effect of electroacupuncture on neural myelin sheaths is mediated via promotion of oligodendrocyte proliferation and inhibition of oligodendrocyte death after compressed spinal cord injury," Molecular Neurobiology, 2014.

[141] C. C. Stolt, A. Schlierf, P. Lommes et al., "SoxD proteins influence multiple stages of oligodendrocyte development and modulate SoxE protein function," Developmental Cell, vol. 11, no. 5, pp. 697-709, 2006.

[142] M. Finzsch, C. C. Stolt, P. Lommes, and M. Wegner, "Sox9 and Sox10 influence survival and migration of oligodendrocyte precursors in the spinal cord by regulating PDGF receptor alpha expression," Development, vol. 135, no. 4, pp. 637-646, 2008.

[143] J. Hornig, F. Fröb, M. R. Vogl, I. Hermans-Borgmeyer, E. R. Tamm, and M. Wegner, "The transcription factors Sox10 and Myrf define an essential regulatory network module in differentiating oligodendrocytes," PLoS Genetics, vol. 9, no. 10, Article ID e1003907, 2013.

[144] M. Küspert, A. Hammer, M. R. Bösl, and M. Wegner, “Olig2 regulates Sox10 expression in oligodendrocyte precursors through an evolutionary conserved distal enhancer," Nucleic Acids Research, vol. 39, no. 4, pp. 1280-1293, 2011.

[145] S.-Z. Wang, J. Dulin, H. Wu et al., "An oligodendrocyte-specific zinc-finger transcription regulator cooperates with Olig2 to promote oligodendrocyte differentiation," Development, vol. 133, no. 17, pp. 3389-3398, 2006.

[146] J. R. Wrathall, W. Li, and L. D. Hudson, "Myelin gene expression after experimental contusive spinal cord injury," The Journal of Neuroscience, vol. 18, no. 21, pp. 8780-8793, 1998.

[147] J. A. Nielsen, J. A. Berndt, L. D. Hudson, and R. C. Armstrong, "Myelin transcription factor 1 (Myt1) modulates the proliferation and differentiation of oligodendrocyte lineage cells," Molecular and Cellular Neuroscience, vol. 25, no. 1, pp. 111-123, 2004.

[148] M. Sugimori, M. Nagao, C. M. Parras et al., "Ascll is required for oligodendrocyte development in the spinal cord," Development, vol. 135, no. 7, pp. 1271-1281, 2008.

[149] M. Wegner, "A matter of identity: transcriptional control in oligodendrocytes," Journal of Molecular Neuroscience, vol. 35, no. 1, pp. 3-12, 2008.

[150] Y. He, J. Dupree, J. Wang et al., “The transcription factor Yin Yang 1 is essential for oligodendrocyte progenitor differentiation," Neuron, vol. 55, no. 2, pp. 217-230, 2007.

[151] R. Tripathi and D. M. McTigue, "Prominent oligodendrocyte genesis along the border of spinal contusion lesions," Glia, vol. 55, no. 7, pp. 698-711, 2007. 
[152] J. M. Lytle, R. Chittajallu, J. R. Wrathall, and V. Gallo, "NG2 cell response in the CNP-EGFP mouse after contusive spinal cord injury," Glia, vol. 57, no. 3, pp. 270-285, 2009.

[153] Z. J. Chen, M. Negra, A. Levine, Y. Ughrin, and J. M. Levine, "Oligodendrocyte precursor cells: reactive cells that inhibit axon growth and regeneration," Journal of Neurocytology, vol. 31, no. 6-7, pp. 481-495, 2002.

[154] D. M. McTigue, P. Wei, and B. T. Stokes, "Proliferation of NG2-positive cells and altered oligodendrocyte numbers in the contused rat spinal cord," Journal of Neuroscience, vol. 21, no. 10, pp. 3392-3400, 2001.

[155] K. Ishii, M. Toda, Y. Nakai et al., "Increase of oligodendrocyte progenitor cells after spinal cord injury," Journal of Neuroscience Research, vol. 65, no. 6, pp. 500-507, 2001.

[156] L. J. Zai and J. R. Wrathall, "Cell proliferation and replacement following contusive spinal cord injury," Glia, vol. 50, no. 3, pp. 247-257, 2005.

[157] F. R. Sahinkaya, L. M. Milich, and D. M. McTigue, "Changes in NG2 cells and oligodendrocytes in a new model of intraspinal hemorrhage," Experimental Neurology, vol. 255, pp. 113-126, 2014.

[158] G. Wolswijk and M. Noble, "Identification of an adult-specific glial progenitor cell,” Development, vol. 105, no. 2, pp. 387-400, 1989.

[159] W. M. Carroll, A. R. Jennings, and L. J. Ironside, "Identification of the adult resting progenitor cell by autoradiographic tracking of oligodendrocyte precursors in experimental CNS demyelination," Brain, vol. 121, no. 2, pp. 293-302, 1998.

[160] J. R. Siebert, D. J. Stelzner, and D. J. Osterhout, "Chondroitinase treatment following spinal contusion injury increases migration of oligodendrocyte progenitor cells," Experimental Neurology, vol. 231, no. 1, pp. 19-29, 2011.

[161] S. K. Ludwin and D. A. Bakker, "Can oligodendrocytes attached to myelin proliferate?" The Journal of Neuroscience, vol. 8, no. 4, pp. 1239-1244, 1988.

[162] H. S. Keirstead and W. F. Blakemore, "Identification of postmitotic oligodendrocytes incapable of remyelination within the demyelinated adult spinal cord," Journal of Neuropathology and Experimental Neurology, vol. 56, no. 11, pp. 1191-1201, 1997.

[163] S. H. Kang, M. Fukaya, J. K. Yang, J. D. Rothstein, and D. E. Bergles, "NG2 ${ }^{+}$CNS glial progenitors remain committed to the oligodendrocyte lineage in postnatal life and following neurodegeneration," Neuron, vol. 68, no. 4, pp. 668-681, 2010.

[164] M. Watanabe, Y. Toyama, and A. Nishiyama, "Differentiation of proliferated NG2-positive glial progenitor cells in a remyelinating lesion," Journal of Neuroscience Research, vol. 69, no. 6, pp. 826-836, 2002.

[165] S. Lacroix, L. K. Hamilton, A. Vaugeois et al., "Central canal ependymal cells proliferate extensively in response to traumatic spinal cord injury but not demyelinating lesions," PLoS ONE, vol. 9, no. 1, Article ID e85916, 2014.

[166] F. Barnabé-Heider, C. Göritz, H. Sabelström et al., "Origin of new glial cells in intact and injured adult spinal cord," Cell Stem Cell, vol. 7, no. 4, pp. 470-482, 2010.

[167] L. F. Corns, L. Atkinson, J. Daniel et al., "Cholinergic enhancement of cell proliferation in the postnatal neurogenic niche of the mammalian spinal cord," Stem Cells, 2015.
[168] J. D. Guest, E. D. Hiester, and R. P. Bunge, "Demyelination and Schwann cell responses adjacent to injury epicenter cavities following chronic human spinal cord injury," Experimental Neurology, vol. 192, no. 2, pp. 384-393, 2005.

[169] J. M. Ruckh, J.-W. Zhao, J. L. Shadrach et al., "Rejuvenation of regeneration in the aging central nervous system," Cell Stem Cell, vol. 10, no. 1, pp. 96-103, 2012.

[170] L. Sun, S. Liu, Q. Sun et al., "Inhibition of TROY promotes OPC differentiation and increases therapeutic efficacy of OPC graft for spinal cord injury," Stem Cells and Development, vol. 23, no. 17, pp. 2104-2118, 2014.

[171] J. R. Plemel, S. B. Manesh, J. S. Sparling, and W. Tetzlaff, "Myelin inhibits oligodendroglial maturation and regulates oligodendrocytic transcription factor expression," Glia, vol. 61, no. 9, pp. 1471-1487, 2013.

[172] T. Kondo and M. C. Raff, "A role for Noggin in the development of oligodendrocyte precursor cells," Developmental Biology, vol. 267, no. 1, pp. 242-251, 2004.

[173] Q. Xiao, Y. Du, W. Wu, and H. K. Yip, "Bone morphogenetic proteins mediate cellular response and, together with Noggin, regulate astrocyte differentiation after spinal cord injury," Experimental Neurology, vol. 221, no. 2, pp. 353-366, 2010.

[174] J. K. Sabo, T. D. Aumann, D. Merlo, T. J. Kilpatrick, and H. S. Cate, "Remyelination is altered by bone morphogenic protein signaling in demyelinated lesions," Journal of Neuroscience, vol. 31, no. 12, pp. 4504-4510, 2011.

[175] S. Jepson, B. Vought, C. H. Gross et al., "LINGO-1, a transmembrane signaling protein, inhibits oligodendrocyte differentiation and myelination through intercellular self-interactions," The Journal of Biological Chemistry, vol. 287, no. 26, pp. 2218422195, 2012.

[176] J. L. Mason and J. E. Goldman, "A2 $25^{+}$and $\mathrm{O}^{+}$cycling progenitors in the adult forebrain white matter respond differentially to PDGF-AA, FGF-2, and IGF-1," Molecular and Cellular Neuroscience, vol. 20, no. 1, pp. 30-42, 2002.

[177] B. Ji, M. Li, W.-T. Wu et al., "LINGO-1 antagonist promotes functional recovery and axonal sprouting after spinal cord injury," Molecular and Cellular Neuroscience, vol. 33, no. 3, pp. 311-320, 2006.

[178] Q.-L. Fu, B. Hu, X. Li et al., "LINGO-1 negatively regulates TrkB phosphorylation after ocular hypertension," European Journal of Neuroscience, vol. 31, no. 6, pp. 1091-1097, 2010.

[179] Z. Su, Y. Yuan, J. Chen et al., "Reactive astrocytes inhibit the survival and differentiation of oligodendrocyte precursor cells by secreted TNF- $\alpha$," Journal of Neurotrauma, vol. 28, no. 6, pp. 1089-1100, 2011.

[180] R. H. Woodruff, M. Fruttiger, W. D. Richardson, and R. J. M. Franklin, "Platelet-derived growth factor regulates oligodendrocyte progenitor numbers in adult CNS and their response following CNS demyelination," Molecular and Cellular Neuroscience, vol. 25, no. 2, pp. 252-262, 2004.

[181] W. Tetzlaff, E. B. Okon, S. Karimi-Abdolrezaee et al., "A systematic review of cellular transplantation therapies for spinal cord injury," Journal of Neurotrauma, vol. 28, no. 8, pp. 16111682, 2011.

[182] E. M. Medina-Rodríguez, F. J. Arenzana, A. Bribián, and F. de Castro, "Protocol to isolate a large amount of functional oligodendrocyte precursor cells from the cerebral cortex of 
adult mice and humans," PLoS ONE, vol. 8, no. 11, Article ID e81620, 2013.

[183] T. Deacon, J. Dinsmore, L. C. Costantini, J. Ratliff, and O. Isacson, "Blastula-stage stem cells can differentiate into dopaminergic and serotonergic neurons after transplantation," Experimental Neurology, vol. 149, no. 1, pp. 28-41, 1998.

[184] S. Kriks, J.-W. Shim, J. Piao et al., "Dopamine neurons derived from human ES cells efficiently engraft in animal models of Parkinson's disease," Nature, vol. 480, no. 7378, pp. 547-551, 2011.

[185] G. I. Nistor, M. O. Totoiu, N. Haque, M. K. Carpenter, and H. S. Keirstead, "Human embryonic stem cells differentiate into oligodendrocytes in high purity and myelinate after spinal cord transplantation," Glia, vol. 49, no. 3, pp. 385-396, 2005.

[186] N. Li, L. Tian, W. Wu et al., "Regional hypothermia inhibits spinal cord somatosensory-evoked potentials without neural damage in uninjured rats," Journal of Neurotrauma, vol. 30, no. 15, pp. 1325-1333, 2013.

[187] K. Takahashi, K. Tanabe, M. Ohnuki et al., "Induction of pluripotent stem cells from adult human fibroblasts by defined factors," Cell, vol. 131, no. 5, pp. 861-872, 2007.

[188] F. J. Najm, A. M. Lager, A. Zaremba et al., "Transcription factor-mediated reprogramming of fibroblasts to expandable, myelinogenic oligodendrocyte progenitor cells," Nature Biotechnology, vol. 31, no. 5, pp. 426-433, 2013.

[189] H. Hentze, P. L. Soong, S. T. Wang, B. W. Phillips, T. C. Putti, and N. R. Dunn, "Teratoma formation by human embryonic stem cells: evaluation of essential parameters for future safety studies," Stem Cell Research, vol. 2, no. 3, pp. 198-210, 2009.

[190] T. Okarma, "Interview with Thomas Okarma, M.D., Ph.D.; CEO, Geron," Rejuvenation Research, vol. 12, no. 4, pp. 295-300, 2009.

[191] T. Yilmaz and E. Kaptanoğlu, "Current and future medical therapeutic strategies for the functional repair of spinal cord injury," World Journal of Orthopaedics, vol. 6, no. 1, pp. 42-55, 2015.

[192] R. P. Salewski, R. A. Mitchell, L. Li et al., "Transplantation of induced pluripotent stem cell-derived neural stem cells mediate functional recovery following thoracic spinal cord injury through remyelination of axons," Stem Cells Translational Medicine, vol. 4, no. 7, pp. 743-754, 2015.

[193] S. Karimi-Abdolrezaee, D. Schut, J. Wang, and M. G. Fehlings, "Chondroitinase and growth factors enhance activation and oligodendrocyte differentiation of endogenous neural precursor cells after spinal cord injury," PLoS ONE, vol. 7, no. 5, Article ID e37589, 2012.

[194] L. X. Zhang, Y. M. Yin, Z. Q. Zhang, and L. X. Deng, "Grafted bone marrow stromal cells: a contributor to glial repair after spinal cord injury," The Neuroscientist, vol. 21, no. 3, pp. 277-289, 2015.

[195] H. Gabr, W. A. El-Kheir, H. A. Farghali et al., "Intrathecal transplantation of autologous adherent bone marrow cells induces functional neurological recovery in a canine model of spinal cord injury," Cell Transplantation. In press.

[196] J. S. Sparling, F. Bretzner, J. Biernaskie et al., "Schwann cells generated from neonatal skin-derived precursors or neonatal peripheral nerve improve functional recovery after acute transplantation into the partially injured cervical spinal cord of the rat," The Journal of Neuroscience, vol. 35, no. 17, pp. 6714-6730, 2015.
[197] H. Kanno, D. D. Pearse, H. Ozawa, E. Itoi, and M. B. Bunge, "Schwann cell transplantation for spinal cord injury repair: its significant therapeutic potential and prospectus," Reviews in the Neurosciences, vol. 26, no. 2, pp. 121-128, 2015.

[198] K. Iwatsuki, T. Yoshimine, H. Kishima et al., "Transplantation of olfactory mucosa following spinal cord injury promotes recovery in rats," NeuroReport, vol. 19, no. 13, pp. 1249-1252, 2008.

[199] J. Lu, F. Féron, A. Mackay-Sim, and P. M. E. Waite, “Olfactory ensheathing cells promote locomotor recovery after delayed transplantation into transected spinal cord," Brain, vol. 125, no. 1, pp. 14-21, 2002.

[200] C. Lima, J. Pratas-Vital, P. Escada, A. Hasse-Ferreira, C. Capucho, and J. D. Peduzzi, "Olfactory mucosa autografts in human spinal cord injury: a pilot clinical study," Journal of Spinal Cord Medicine, vol. 29, no. 3, pp. 191-203, 2006.

[201] Y. Rao, W. Zhu, Y. Guo et al., "Long-term outcome of olfactory ensheathing cell transplantation in six patients with chronic complete spinal cord injury," Cell Transplantation, vol. 22, supplement 1, pp. S21-S25, 2013.

[202] Z. C. Zheng, G. F. Liu, Y. X. Chen, and S. G. Wei, “Olfactory ensheathing cell transplantation improves sympathetic skin responses in chronic spinal cord injury," Neural Regeneration Research, vol. 8, no. 30, pp. 2849-2855, 2013.

[203] S. Wang, J. Lu, Y. A. Li et al., "Autologous olfactory lamina propria transplantation for chronic spinal cord injury: threeyear follow-up outcomes from a prospective double blinded clinical trial," Cell Transplantation. In press.

[204] J. R. Faulkner, J. E. Herrmann, M. J. Woo, K. E. Tansey, N. B. Doan, and M. V. Sofroniew, "Reactive astrocytes protect tissue and preserve function after spinal cord injury," The Journal of Neuroscience, vol. 24, no. 9, pp. 2143-2155, 2004.

[205] C. Schachtrup, J. K. Ryu, M. J. Helmrick et al., "Fibrinogen triggers astrocyte scar formation by promoting the availability of active TGF-beta after vascular damage," The Journal of Neuroscience, vol. 30, no. 17, pp. 5843-5854, 2010.

[206] I. B. Wanner, M. A. Anderson, B. Song et al., "Glial scar borders are formed by newly proliferated, elongated astrocytes that interact to corral inflammatory and fibrotic cells via STAT3dependent mechanisms after spinal cord injury," Journal of Neuroscience, vol. 33, no. 31, pp. 12870-12886, 2013.

[207] S. Hermanns, N. Klapka, and H. W. Müller, “The collagenous lesion scar-an obstacle for axonal regeneration in brain and spinal cord injury," Restorative Neurology and Neuroscience, vol. 19, no. 1-2, pp. 139-148, 2001.

[208] A. Rolls, R. Shechter, and M. Schwartz, "The bright side of the glial scar in CNS repair," Nature Reviews Neuroscience, vol. 10, no. 3, pp. 235-241, 2009.

[209] J. W. Fawcett, "Overcoming inhibition in the damaged spinal cord," Journal of Neurotrauma, vol. 23, no. 3-4, pp. 371-383, 2006.

[210] A. Rasouli, N. Bhatia, P. Dinh, K. Cahill, S. Suryadevara, and R. Gupta, "Resection of glial scar following spinal cord injury," Journal of Orthopaedic Research, vol. 27, no. 7, pp. 931-936, 2009.

[211] J. W. Fawcett and R. A. Asher, "The glial scar and central nervous system repair," Brain Research Bulletin, vol. 49, no. 6, pp. 377391, 1999. 
[212] T. Laabs, D. Carulli, H. M. Geller, and J. W. Fawcett, "Chondroitin sulfate proteoglycans in neural development and regeneration," Current Opinion in Neurobiology, vol. 15, no. 1, pp. 116120,2005

[213] J. R. Siebert, A. C. Steencken, and D. J. Osterhout, "Chondroitin sulfate proteoglycans in the nervous system: inhibitors to repair," BioMed Research International, vol. 2014, Article ID 845323, 15 pages, 2014.

[214] Z. J. Chen, Y. Ughrin, and J. M. Levine, "Inhibition of axon growth by oligodendrocyte precursor cells," Molecular and Cellular Neuroscience, vol. 20, no. 1, pp. 125-139, 2002.

[215] Y. M. Ughrin, Z. J. Chen, and J. M. Levine, "Multiple regions of the NG2 proteoglycan inhibit neurite growth and induce growth cone collapse," Journal of Neuroscience, vol. 23, no. 1, pp. 175-186, 2003.

[216] R. de Castro Jr., R. Tajrishi, J. Claros, and W. B. Stallcup, "Differential responses of spinal axons to transection: influence of the NG2 proteoglycan," Experimental Neurology, vol. 192, no. 2, pp. 299-309, 2005.

[217] A. M. Tan, M. Colletti, A. T. Rorai, J. H. P. Skene, and J. M. Levine, "Antibodies against the NG2 proteoglycan promote the regeneration of sensory axons within the dorsal columns of the spinal cord," Journal of Neuroscience, vol. 26, no. 18, pp. 47294739, 2006.

[218] I. Novotna, L. Slovinska, I. Vanicky, M. Cizek, J. Radonak, and D. Cizkova, "IT delivery of ChABC modulates NG2 and promotes GAP-43 axonal regrowth after spinal cord injury," Cellular and Molecular Neurobiology, vol. 31, no. 8, pp. 1129-1139, 2014.

[219] H. A. Petrosyan, A. S. Hunanyan, V. Alessi, L. Schnell, J. Levine, and V. L. Arvanian, "Neutralization of inhibitory molecule NG2 improves synaptic transmission, retrograde transport, and locomotor function after spinal cord injury in adult rats," The Journal of Neuroscience, vol. 33, no. 9, pp. 4032-4043, 2013.

[220] J. R. Siebert and D. J. Osterhout, "The inhibitory effects of chondroitin sulfate proteoglycans on oligodendrocytes," Journal of Neurochemistry, vol. 119, no. 1, pp. 176-188, 2011.

[221] S. A. Busch and J. Silver, "The role of extracellular matrix in CNS regeneration," Current Opinion in Neurobiology, vol. 17, no. 1, pp. 120-127, 2007.

[222] J. C. Pendleton, M. J. Shamblott, D. S. Gary et al., "Chondroitin sulfate proteoglycans inhibit oligodendrocyte myelination through PTPsigma," Experimental Neurology, vol. 247, pp. 113-121, 2013.

[223] A. L. Hawthorne, H. Hu, B. Kundu et al., "The unusual response of serotonergic neurons after CNS injury: lack of axonal dieback and enhanced sprouting within the inhibitory environment of the glial scar," Journal of Neuroscience, vol. 31, no. 15, pp. 56055616, 2011. 


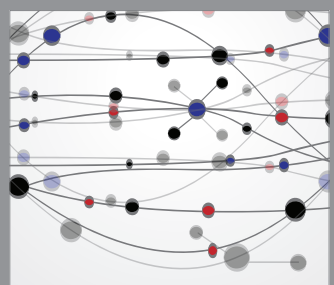

The Scientific World Journal
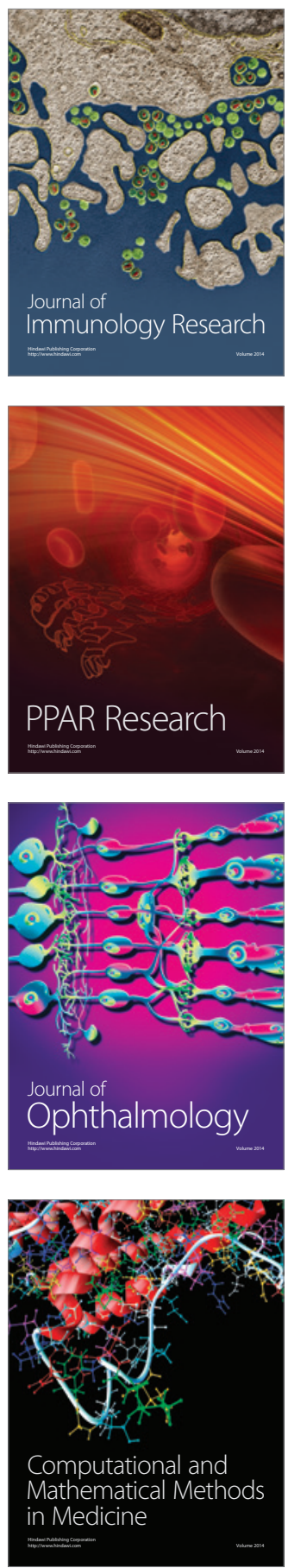

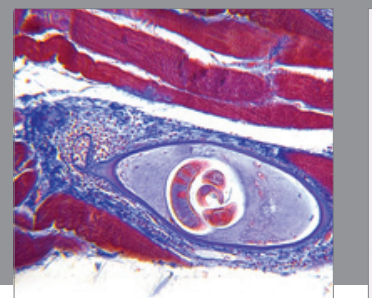

Gastroenterology

Research and Practice
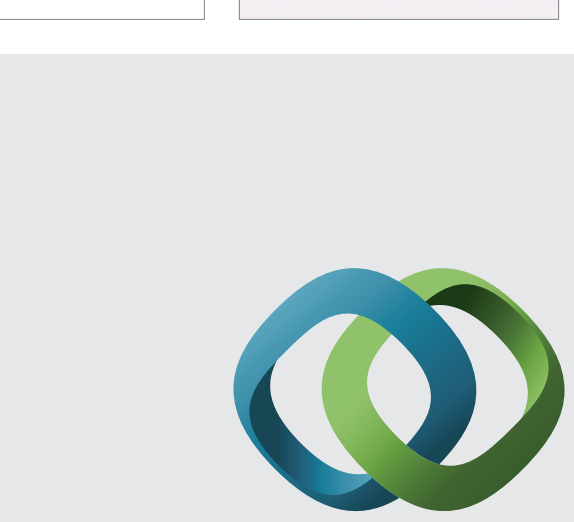

\section{Hindawi}

Submit your manuscripts at

http://www.hindawi.com
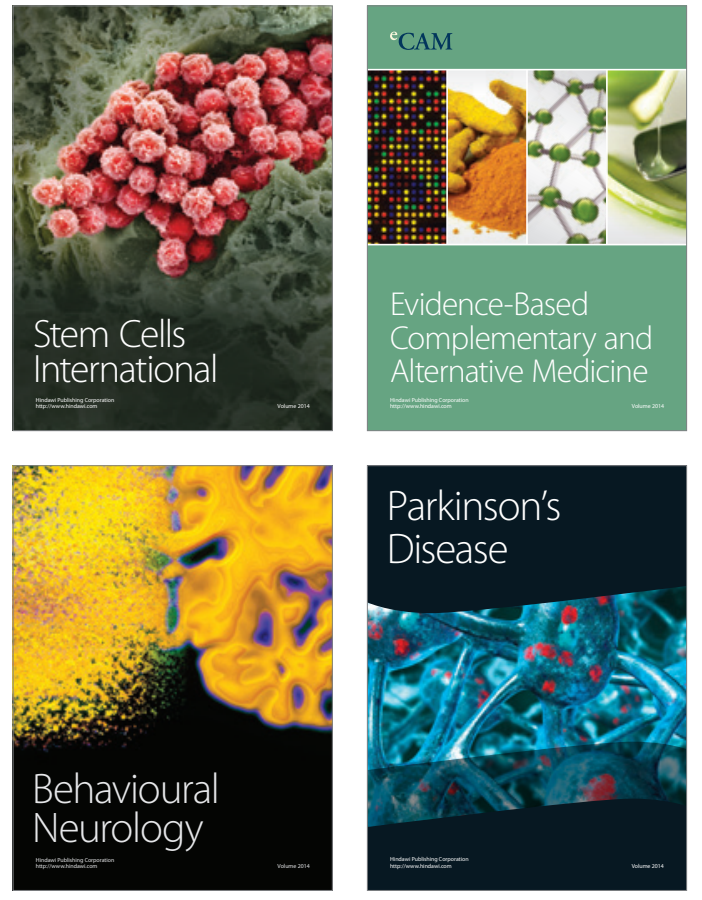
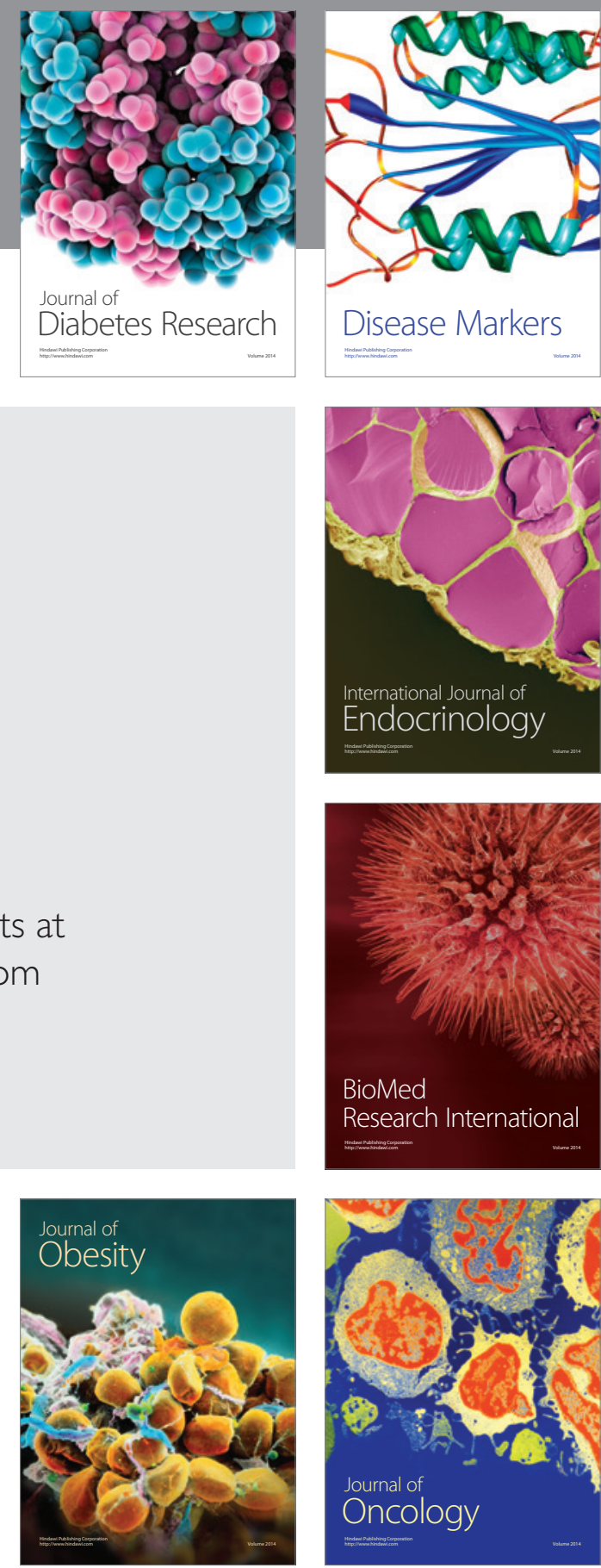

Disease Markers
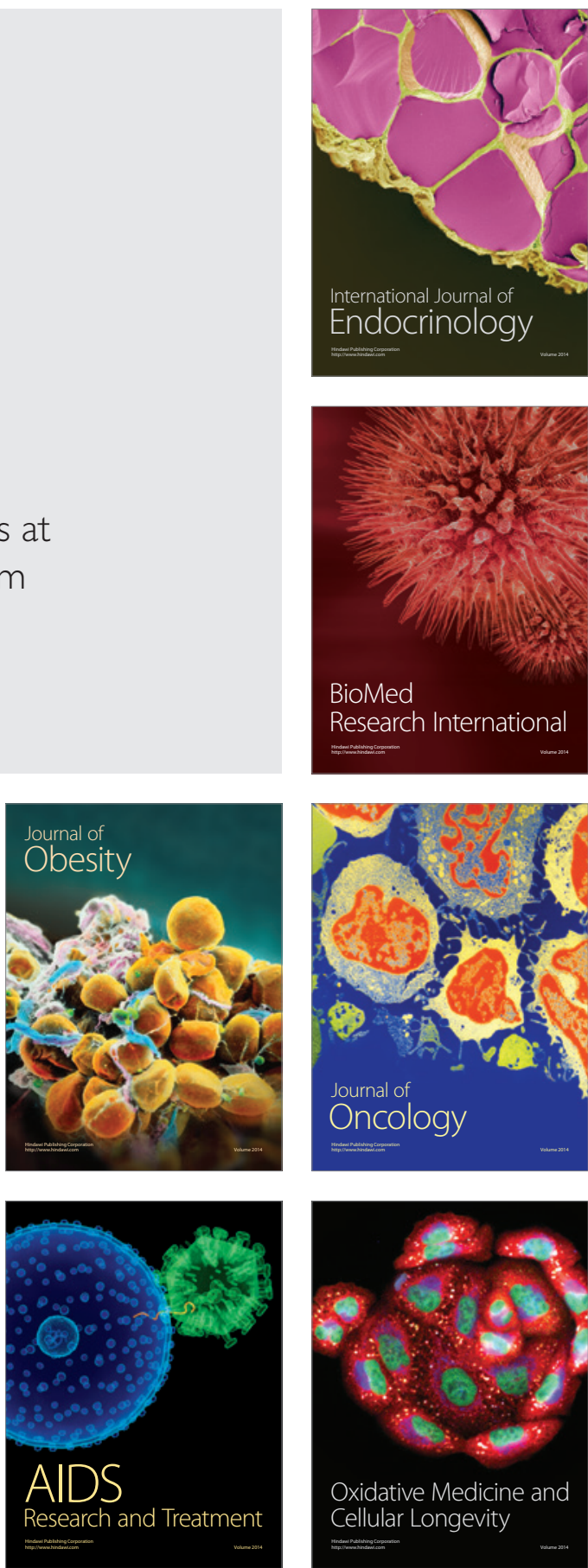